\title{
The Protein Tyrosine Phosphatase Shp2 Regulates Oligodendrocyte Differentiation and Early Myelination and Contributes to Timely Remyelination
}

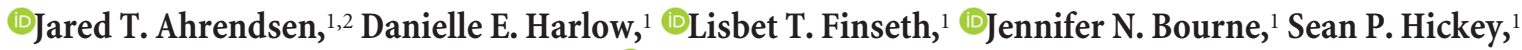 \\ Elizabeth A. Gould, ${ }^{1}$ Cecilia M. Culp, ${ }^{1}$ and ${ }^{\circ}$ Wendy B. Macklinn ${ }^{1,2}$ \\ ${ }^{1}$ Department of Cell and Developmental Biology, and ${ }^{2}$ Neuroscience Graduate Program and Medical Scientist Training Program, University of Colorado \\ School of Medicine, Aurora, Colorado 80045
}

\begin{abstract}
Shp2 is a nonreceptor protein tyrosine phosphatase that has been shown to influence neurogenesis, oligodendrogenesis, and oligodendrocyte differentiation. Furthermore, Shp2 is a known regulator of the Akt/mammalian target of rapamycin and ERK signaling pathways in multiple cellular contexts, including oligodendrocytes. Its role during later postnatal CNS development or in response to demyelination injury has not been examined. Based on the current studies, we hypothesize that Shp2 is a negative regulator of CNS myelination. Using transgenic mouse technology, we show that Shp2 is involved in oligodendrocyte differentiation and early myelination, but is not necessary for myelin maintenance. We also show that Shp2 regulates the timely differentiation of oligodendrocytes following lysolecithin-induced demyelination, although apparently normal remyelination occurs at a delayed time point. These data suggest that Shp2 is a relevant therapeutic target in demyelinating diseases such as multiple sclerosis.
\end{abstract}

Key words: myelination; oligodendrocyte; remyelination; Shp2

Significance Statement

In the present study, we show that the protein phosphatase Shp2 is an important mediator of oligodendrocyte differentiation and myelination, both during developmental myelination as well as during myelin regeneration. We provide important insight into the signaling mechanisms regulating myelination and propose that Shp2 acts as a transient brake to the developmental myelination process. Furthermore, we show that Shp2 regulates oligodendrocyte differentiation following demyelination and therefore has important therapeutic implications in diseases such as multiple sclerosis.

\section{Introduction}

The coordinated production of myelin is required for proper development and function of the nervous system. However, the molecular mechanisms directing these events in vivo are not well understood. The phosphoinositide 3 kinase/Akt/mammalian target of rapamycin (mTOR) signaling pathway is important for driving active myelination in the CNS. The overexpression of constitutively active Akt within oligodendrocytes results in CNS hypermyelina-

Received Aug. 27, 2016; revised Nov. 1, 2017; accepted Nov. 26, 2017.

Author contributions: J.T.A., D.E.H., and W.B.M. designed research; J.T.A., D.E.H., L.T.F., J.N.B., S.P.H., E.A.G., and C.M.C. performed research; J.T.A. and W.B.M. analyzed data; J.T.A. and W.B.M. wrote the paper.

This work was supported by National Institutes of Health Grants F31-NS-081834 (to J.T.A.); and R01-NS-056147 and NS-028803 (to W.B.M.)

The authors declare no competing financial interests.

Correspondence should be addressed to Dr. Wendy B. Macklin, Department of Cell and Developmental Biology, University of Colorado School of Medicine, 12801 East 17th Avenue, Mail Stop 8108, Aurora, C0 80045. E-mail: Wendy.Macklin@ucdenver.edu.

DOI:10.1523/JNEUROSCI.2864-16.2017

Copyright $\odot 2018$ the authors $\quad 0270-6474 / 18 / 380787-16 \$ 15.00 / 0$ tion and can be rescued by treatment with the mTOR inhibitor rapamycin (Flores et al., 2008; Narayanan et al., 2009). The signaling mechanisms that downregulate Akt signaling in oligodendrocytes after the appropriate amount of myelin has been formed remain unknown.

To identify molecules that downregulate Akt signaling driving CNS myelination, we previously screened multiple negative regulators of Akt signaling for developmental expression profiles suggestive of a role in downregulating the myelination process. The protein tyrosine phosphatase Shp2 was identified as a putative negative regulator of myelination (Ahrendsen and Macklin, 2013). Shp2, also known as PTPN11, is traditionally considered a positive regulator of ERK signaling (Navis et al., 2010); however, Shp2 is now known also to negatively regulate Akt/mTOR signaling in some cellular contexts, including oligodendrocytes (Liu et al., 2011; Marin et al., 2011; Nagata et al., 2012).

Shp2 influences neural and glial specification during early nervous system development (Coskun et al., 2007; Grossmann et al., 2009). In particular, Shp 2 expression by oligodendrocytes influences 
in vitro differentiation of primary oligodendrocytes via Akt and ERK1/2 signaling (Liu et al., 2011). Shp2 activity maintains cultured oligodendrocyte precursor cells (OPCs) in a state of proliferation and opposes the prodifferentiation effects of Shp 1 (Kuo et al., 2010). Likewise, Shp2 conditional knockout decreases OPC proliferation and generation in vivo, but its effects during later stages of oligodendrocyte differentiation and myelination could not be analyzed in previous studies due to early postnatal lethality in experimental animals (Zhu et al., 2010; Ehrman et al., 2014). Interestingly, the transgenic expression of a Shp2 gain-of-function mutation in oligodendrocytes results in elevated numbers of OPCs, fewer myelinated axons, and abnormal myelination in the forebrain (Ehrman et al., 2014).

Together, these results suggest that oligodendrocyte Shp2 has stage-specific effects, influencing OPC proliferation, oligodendrocyte differentiation, and myelination. However, the role of Shp2 during myelination specifically has not been characterized because of the early postnatal lethality in transgenic animals previously studied. Furthermore, the role of Shp2 during remyelination has not been examined. The current studies were undertaken to test the hypothesis that Shp2 negatively regulates myelination and remyelination by downregulating Akt/mTOR signaling. Using conditional and inducible transgenic mouse technologies, we show here that oligodendrocyte Shp2 influences oligodendrocyte differentiation and the early stages of myelination. However, the loss of Shp2 in oligodendrocytes during early myelination had little impact on Akt/mTOR signaling but rather resulted in elevated focal adhesion kinase (FAK) signaling. Oligodendrocyte Shp2 signaling was not necessary for long-term maintenance of CNS myelin. During remyelination, Shp2 is necessary for timely oligodendrocyte differentiation following lysolecithin-induced demyelination, although, over time, apparent normal remyelination is restored. These studies demonstrate that Shp2 influences the early stages of myelination and could function as part of the braking mechanism of CNS myelination. Furthermore, its role in oligodendrocyte differentiation during remyelination makes Shp2 an attractive therapeutic target for demyelinating disorders, such as multiple sclerosis.

\section{Materials and Methods}

Animals. All experimental protocols were approved by the Institutional Animal Care and Use Committee at the University of Colorado School of Medicine and conformed to the National Institutes of Health Guidelines for the Care and Use of Animals in Research. For Cre-mediated recombination of Shp2 in oligodendrocyte lineage cells, mice of either sex carrying the floxed allele of $\operatorname{Sh} p 2\left(\operatorname{Sh} p 2^{f l / f l}\right.$; Mutant Mouse Regional Resource Center; Zhang et al., 2004) were bred to $C N P^{\text {cre/+ }}$ mice (Lappe-Siefke et al., 2003) to generate the following genotypes: $C N P^{c r e /+} ; \operatorname{Sh} p 2^{f l / f l}$ [experimental animals (cKO)], $C N P^{+/+} ; S h p 2^{f / f / l}$ and $C N P^{c r e /+} ; S h p 2^{f l /+}$ [wild-type controls (WT)]. For Cre-mediated, tamoxifen-inducible recombination of Shp2 in oligodendrocyte lineage cells, $S h p 2^{f l f l}$ mice were bred to $P L P^{\text {creERT/+ }}$ mice (Doerflinger et al., 2003) to generate $P L P^{c r e E R T /+} ; S h p 2^{f l / f l}$ and $P L P^{+/+}$; $S h p 2^{f l / f l}$ animals. All animals were maintained on a C57BL/6 background.

All zebrafish experiments undertaken in this study were approved by the Institutional Animal Care and Use Committee at the University of Colorado School of Medicine. Embryos of either sex were raised at $28.5^{\circ} \mathrm{C}$ in embryo media (EM) and staged according to hours postfertilization (hpf), days postfertilization (dpf), and morphological criteria (Kimmel et al., 1995).

Tamoxifen administration. Tamoxifen (Sigma-Aldrich) was dissolved in sunflower oil/ethanol (10:1) to a final concentration of $10 \mathrm{mg} / \mathrm{ml}$. For developmental studies, mice received intraperitoneal injections of $100 \mu \mathrm{g}$ of tamoxifen per gram of mouse weight once a day for 10 consecutive days, starting at either postnatal day 25 (P25) or P85. As vehicle control, sunflower oil/ethanol (10:1) was injected over the same time frame. For lysolecithin studies, mice received the same dosing for 7 consecutive days starting $3 \mathrm{~d}$ after the lysolecithin procedure.

Lysolecithin-induced demyelination. PLP ${ }^{\text {creERT/+}} ;$; Shp $2^{f l f l}$ and $P L P^{+/+}$; $S h p 2^{f l f l}$ littermates $8-12$ weeks old were used for lysolecithin-induced demyelination studies. Anesthesia was induced with intraperitoneal injection of ketamine/xylazine. Dorsal laminectomy was performed at the T10-T11 level. A Hamilton needle was positioned just lateral to the central vein, advanced $0.5 \mathrm{~mm}$ deep into the dorsal columns, and $1.0 \mu \mathrm{l}$ of $1 \%$ lysolecithin ( $\mathrm{L}-\alpha$-lysophosphatidylcholine, Sigma-Aldrich) in saline was injected into the dorsal white matter. Saline injections were used for sham controls. The needle was left in place for an additional 2 minutes to avoid back flow of the lysolecithin or PBS. Muscle and skin incisions were sutured with gut and nylon sutures, respectively. To reduce postoperative pain after recovery from anesthesia, animals received a subcutaneous injection of buprenorphine $(1.0 \mathrm{mg} / \mathrm{kg})$. Animals were monitored closely following surgery and were sacrificed for analyses at 14, 21, and $35 \mathrm{~d}$ postlesion (dpl).

Drug inhibitor experiments. PHPS1 (Santa Cruz Biotechnology) and PF 573228 (Tocris Bioscience) were each dissolved in 100\% DMSO at concentrations of 21.5 and $20 \mathrm{~mm}$, respectively. Drugs were diluted in EM to make the following working concentrations: PHPS1 $20 \mu \mathrm{M}$; and PF $57322810 \mu \mathrm{M}$. Each drug had a final concentration of $1 \%$ DMSO, and $1 \%$ DMSO in EM was used as a control solution. Zebrafish drug treatments were initiated at $48 \mathrm{hpf}(2 \mathrm{dpf})$ and replaced with fresh drug every $24 \mathrm{~h}$ until $96 \mathrm{hpf}$ ( $4 \mathrm{dpf}$ ), at which point larvae were collected for protein or internode analysis (see below).

Immunohistochemistry. Mice were briefly anesthetized with isoflurane, and tissue was fixed by transcardial perfusion with PBS followed by $4 \%$ paraformaldehyde (PFA). Brains and spinal cords were dissected, postfixed overnight, and transferred to cryoprotection solution (20\% glycerol in $0.1 \mathrm{~m}$ Sorenson's buffer, $\mathrm{pH}$ 7.6).

The immunohistochemistry (IHC) protocol was adapted from previously described studies (Trapp et al., 1997). Mouse brains were sectioned at $30 \mu \mathrm{m}$ on a sliding microtome, and sections were stored at $4^{\circ} \mathrm{C}$ in cryostorage solution (30\% ethylene glycol, $30 \%$ sucrose, and 1\% PVP-40 in 0.1 M Sorenson's buffer). Free-floating sections were washed in PBS, and antigen retrieval was performed with $10 \mathrm{~mm}$ sodium citrate, $\mathrm{pH}$ 6.0, plus $0.05 \%$ Tween-20 for $10 \mathrm{~min}$ at $550 \mathrm{~W}$ in a PELCO BioWave Pro tissue processor (Ted Pella). Sections were then washed in PBS, permeabilized with $0.3-10 \%$ Triton X-100 (dependent on specific antibodies), blocked with $5 \%$ normal donkey serum, and incubated with primary antibody for $1-3 \mathrm{~d}$ at $4^{\circ} \mathrm{C}$.

Whole zebrafish at $4 \mathrm{dpf}$ were treated with $1 \%$ Tricaine (ethyl 3-aminobenzoate methanesulfonate salt, Sigma-Aldrich) and fixed with $2 \%$ PFA/2\% trichloroacetic acid overnight at $4^{\circ} \mathrm{C}$. Samples were washed in PBST (PBS with $0.1 \%$ Tween-20), permeabilized in ice cold acetone for $8 \mathrm{~min}$, and blocked with $5 \%$ normal donkey serum $/ 2 \%$ bovine serum albumin in PBST before incubation with primary antibody overnight at $4^{\circ} \mathrm{C}$.

The following primary antibodies were used: rabbit anti-Shp2 (Cell Signaling Technology); mouse anti-CC1 (Calbiochem); rabbit anti-myelin oligodendrocyte glycoprotein (MOG; Abcam); mouse anti-SMI94 [myelin basic protein (MBP), Covance]; goat anti-Sox10 (Santa Cruz Biotechnology); rabbit anti-Olig2 (a gift from Dr. Charles Stiles, Harvard University, Cambridge, MA); rat anti-PDGF receptor $\alpha$ (PDGFR $\alpha$; BD Biosciences); mouse anti-3A10 (Developmental Studies Hybridoma Bank); rabbit anti-MBP (a gift from Dr. William Talbot, Stanford University, Palo Alto, CA). For fluorescent IHC, tissue was incubated with the appropriate Alexa Fluor-conjugated secondary antibodies (Jackson ImmunoResearch) for $2 \mathrm{~h}$ at room temperature and mounted on glass slides in Vectashield Mounting Media (Vector Laboratories). For diaminobenzidine (DAB) IHC, sections were incubated with the appropriate biotinylated conjugated secondary antibodies (Jackson ImmunoResearch), followed by incubation with avidin-biotin complex (ABC Reagent, Vector Laboratories). Sections were washed and incubated in diaminobenzidine (DAB Kit, Vector Laboratories), and the myelin staining was amplified by brief exposure to $0.08 \%$ osmium tetroxide. Sections were transferred to $60 \%$ glycerol before mounting on glass slides in $100 \%$ 
glycerol. Images for fluorescent IHC were acquired using a Leica TCS SP5 II confocal microscope using identical imaging parameters between each group within a staining set. Images for DAB IHC were acquired with a Leica DMR Microscope and DFC290HD digital camera using Leica Application Suite software (Leica Microsystems).

Cell counting. For developmental mouse studies, cells were quantified from images acquired in the primary motor cortex. At least four images were taken from each hemisphere per stained section, and at least two sections were stained per animal. Four animals per group were analyzed. Oligodendrocytes were quantified by the expression of oligodendrocyte transcription factor 2 (Olig2). Oligodendrocyte precursor cells were identified by the coexpression of PDGFR $\alpha$ and Olig2. Mature oligodendrocytes were identified by the coexpression of $\mathrm{CC} 1$ and Olig2. For demyelination studies, images were taken at the lesion core in the dorsal white matter tracts. At least two sections were analyzed per animal, with four animals per group. The Cell Counter plug-in on Fiji software (Schindelin et al., 2012) was used for all cell count analyses.

Western blot. Tissue dissected from the oligodendrocyte-enriched corpus callosum (four animals per experimental group) was snap frozen in liquid nitrogen and stored at $-80^{\circ} \mathrm{C}$ until lysis. Tissue was lysed in glass homogenizers in radioimmunoprecipitation assay (RIPA, SigmaAldrich) buffer supplemented with phosphatase inhibitor cocktail (Calbiochem) and protease inhibitor (cOmplete Mini, Roche). For zebrafish studies, 25 whole embryos were combined per experimental group and lysed by sonication $(10 \times 1 \mathrm{~s}$ pulses at $25 \%$ amplitude $)$ in RIPA buffer with the above supplements. The lysates were centrifuged for $10 \mathrm{~min}$ at $4^{\circ} \mathrm{C}$, and the supernatants were collected for protein quantification using a BCA Protein Assay Kit (Thermo Fisher Scientific). The lysates were subjected to SDS-PAGE (4-20\% gradient gel; Bio-Rad), and the proteins transferred to PVDF membranes. The membranes were blocked with 5\% bovine serum albumin in TBS and then incubated with the following antibodies overnight at $4^{\circ} \mathrm{C}$ (all from Cell Signaling Technology, unless otherwise noted): rabbit anti-Shp2; rabbit anti-phospho-Akt (p-Akt) S473; mouse anti-pan Akt; rabbit anti-phospho mTOR S2448; mouse anti-pan mTOR; rabbit anti-phospho ERK1/2; mouse anti-pan ERK; rabbit anti-phospho FAK Y397; rabbit anti-pan FAK; rabbit anti-GAPDH; rabbit anti-MAG (Abcam); mouse anti-SMI94 (MBP, Covance); rat antiproteolipid protein (PLP)/DM20 (Clone AA3; Yamamura et al., 1991). Blots were scanned and quantified using an Odyssey infrared imager (LI-COR).

Electron microscopy. For electron microscopy, mice were perfused with modified Karnovsky's fixative ( $2 \%$ paraformaldehyde $/ 2.5 \%$ glutaraldehyde) in phosphate buffer, $\mathrm{pH}$ 7.4. Brains were removed and immersed in the same fixative overnight. Corpus callosum was isolated from $1 \mathrm{~mm}$ coronal slices of brain between -0.94 and $-2.18 \mathrm{~mm}$ of bregma (Franklin and Paxinos, 2008). Using a PELCO Biowave Pro Tissue Processor (Ted Pella), the tissue was rinsed in $100 \mathrm{~mm}$ cacodylate buffer and then postfixed in a reduced osmium mixture consisting of $1 \%$ osmium tetroxide and $1.5 \%$ potassium ferrocyanide followed by $1 \%$ osmium tetroxide alone. Dehydration was performed in a graded series of acetone dilutions $(50 \%, 70 \%, 90 \%$, and $100 \%)$ containing $2 \%$ uranyl acetate for en bloc staining. Finally, tissue was infiltrated and embedded in Embed 812 (Electron Microscopy Services) and cured for $48 \mathrm{~h}$ at $60^{\circ} \mathrm{C}$. The corpus callosum pieces were oriented such that sections could be cut midline in a sagittal plane. Ultrathin sections $(65 \mathrm{~nm})$ were mounted on copper mesh grids and viewed at $80 \mathrm{kV}$ on a Tecnai G2 transmission electron microscope (FEI). Electron micrographs of the corpus callosum were imaged near the midline.

G-ratio analysis. G-ratios of myelinated fibers were calculated as the ratio of the diameter of the axon to the diameter of the myelinated fiber. Diameters were derived by measuring the respective perimeters using Fiji software. A minimum of 100 axons per animal were quantified, and samples were analyzed from four animals per experimental group.

Internode analysis. To quantify the internode length and number generated per oligodendrocyte, zebrafish embryos were injected with $5 \mathrm{ng}$ of pEXPRESS-mbp:mEGFP.pA.cmcl2:RFP.tol2 and $0.25 \mathrm{ng}$ capped-tol2 mRNA at the one-cell stage. Between 30 and $40 \mathrm{hpf}$, embryos were sorted for GFP fluorescence, dechorionated, and placed in six-well dishes plus
EM. From 48 to $96 \mathrm{hpf}$, embryos were treated with 1\% DMSO plus drug in EM or 1\% DMSO in EM (control), refreshing drug solutions at $72 \mathrm{hpf}$. At $96 \mathrm{hpf}$, treated larvae were anesthetized with $1 \%$ Tricaine, laterally embedded in $1 \%$ low-melt agarose plus Tricaine, and imaged with confocal. The dorsal spinal cord was imaged just above the yolk sack extension at 96-98 hpf time frame. To guarantee clear quantification, only isolated oligodendrocytes lacking labeled neighboring cells were analyzed to make certain all sheaths originated from a single soma. Internode length and the number of internodes per cell were quantified using Imaris Image Analysis Software (Bitplane).

Statistical analysis. Unpaired, two-tailed Student's $t$ test was used to calculate statistical significance between the $\mathrm{cKO}$ and WT groups. For each dataset, normality was assessed using the D'Agonistino and Pearsons normality test. One-way ANOVA with multiple comparisons was used to determine statistical significance between groups in lysolecithin experiments and between zebrafish drug treatment groups in which the internode number was quantified. Internode length did not meet the assumption of normality and was further assessed using the nonparametric Kruskal-Wallis and Dunn's multiple-comparison tests. $p$ Values of $<0.05$ were designated as statistically significant. Graphs represent the mean \pm SEM. Graphs were created and statistical analyses were performed using GraphPad Prism 7 software (www.graphpad.com).

\section{Results}

\section{Shp2 conditional knockout with CNP-driven Cre} recombination

Previous in vivo studies examining the role of Shp2 in oligodendrocytes were limited by early postnatal lethality. Shp2 conditional knock-out mice failed to survive past P21 using either the Olig1-Cre or Olig2-Cre transgenic mice, therefore preventing a detailed characterization of later postnatal development (Zhu et al., 2010; Ehrman et al., 2014). In an attempt to extend the survival of Shp2 conditional knock-out mice, we used the CNP-Cre transgenic mouse, in which recombination occurs later during embryonic development (Genoud et al., 2002; Lappe-Siefke et al., 2003; Furusho et al., 2006). The Shp 2 conditional knockouts (cKO) were smaller than WT littermates (Fig. 1A) and developed extensive shaking and unbalanced movements starting at P10. The shaking phenotype observed is typical for myelin abnormalities during development (Molineaux et al., 1986). Survival was prolonged in these cKO animals to $>4$ weeks of age. Animals were killed by P28 for ethical reasons due to severe hindlimb paralysis rendering the animals unable to properly feed themselves.

To verify the efficiency of Cre-mediated recombination of the floxed Shp2 alleles, Shp2 immunostaining was performed on WT and $\mathrm{cKO}$ brain tissue at P21 (Fig. $1 B, C$ ). Shp 2 immunostaining was detectable in $83.4 \pm 8.6 \%$ of Sox10-positive cells in the corpus callosum of WT animals and in only $7.3 \pm 2.4 \%$ of Sox 10 -positive cells in the corpus callosum of cKO animals (Fig. 1D). Thus, recombination efficiency was $>90 \%$. We also observed significantly less Shp2 protein by Western blot in corpus callosum samples from WT and cKO animals at P14 and P28 (see Fig. 3A). Thus, the Shp2 gene was effectively recombined from oligodendrocyte lineage cells in these $\mathrm{CKO}$ mice.

\section{Delayed oligodendrocyte differentiation in the Shp 2 cKO brain}

To assess the effect of Shp2 cKO on oligodendrocyte generation and differentiation, we used a panel of immunohistochemical markers. Olig2 is a transcription factor expressed by all cells in the oligodendrocyte lineage, PDGFR $\alpha$ is a receptor expressed by OPCs, and $\mathrm{CC} 1$ is a marker for differentiated oligodendrocytes. The analysis shown here was performed in the primary motor cortex, where there is a homogenous and reliably quantifiable population of cells at multiple levels through the brain, and previous studies have shown that this population of cells is a good repre- 

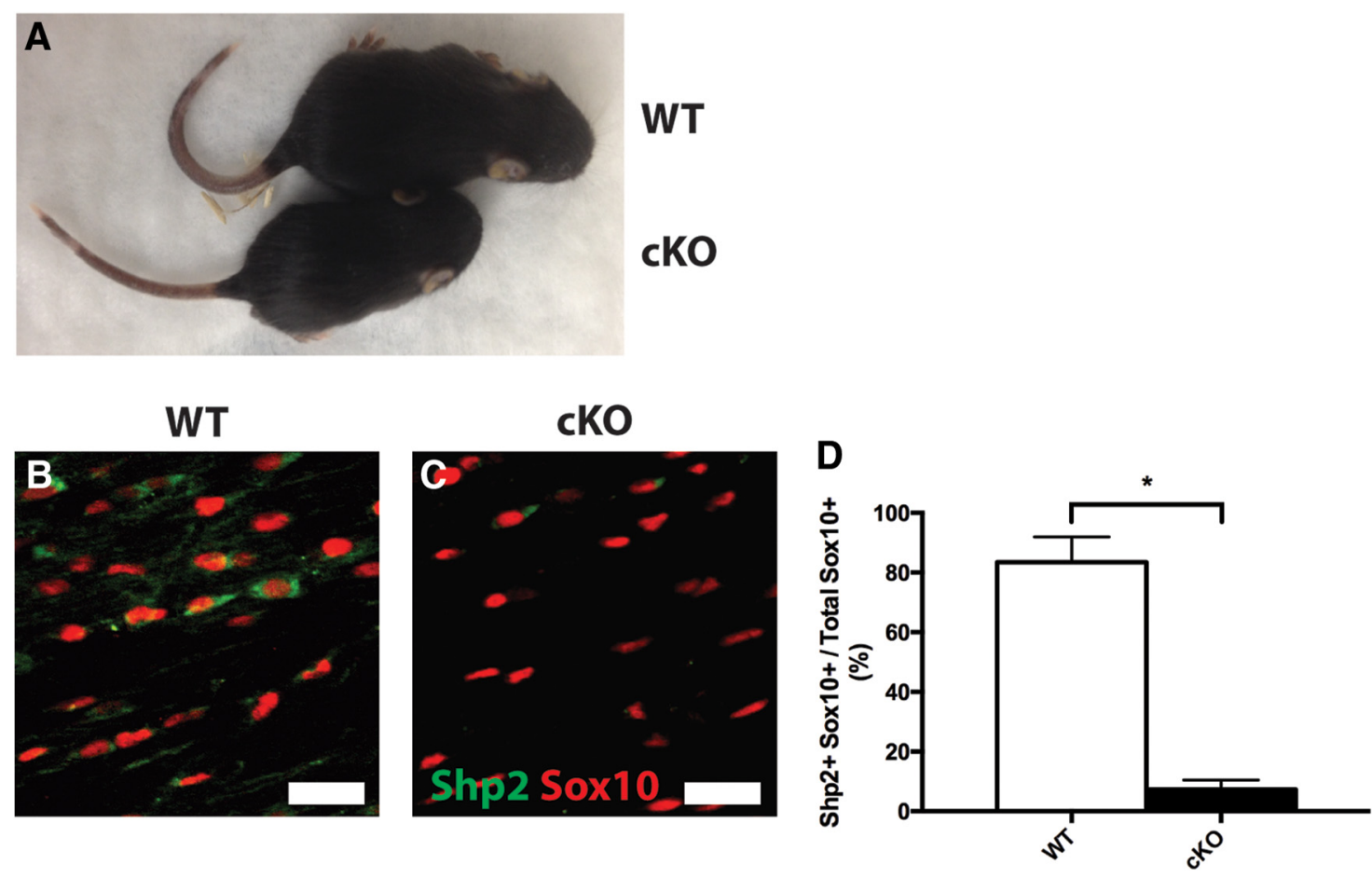

Figure 1. Conditional knockout of Shp2 from oligodendrocytes. $\boldsymbol{A}$, cK0 mice are smaller that wild-type mice. $\boldsymbol{B}, \boldsymbol{C}$, Immunohistochemical analysis of Shp2 (green) expression at P21 in WT oligodendrocytes (Sox10-positive cells, red; $\boldsymbol{B}$ ) and loss in CKO oligodendrocytes (C). D, Quantification of Shp2 colocalization with Sox10 in WT (open bar) and cKO (dark bar) mice. Scale bars, $25 \mu \mathrm{mm}$. $n=3$ animals/group. ${ }^{*} p<0.05$.

sentation of the population in the underlying subcortical white matter (Flores et al., 2008). At P14, there were 30\% fewer Olig2positive cells in the cortex of Shp $2 \mathrm{cKO}$ animals compared with WT controls (Fig. 2A,D,G). Similarly, at P21, we observed 20\% fewer Olig2-positive cells in cKO animals compared with WT controls (Fig. $2 B, E, G$ ). By P28, the number of Olig2-positive cells was not different in $\mathrm{cKO}$ animals compared with WT animals (Fig. 2C, F, G). These data suggest that there are fewer oligodendrocyte lineage cells in the cortex of Shp $2 \mathrm{cKO}$ animals during the first 3 weeks of postnatal development, but the number gradually approaches WT levels by 4 weeks of age.

Because Olig2 does not discriminate between OPCs and mature oligodendrocytes, we quantified the numbers of PDGFR $\alpha /$ Olig2-double-positive OPCs and CC1/Olig2-double-positive mature oligodendrocytes. The number of PDGFR $\alpha$ /Olig2-double-positive cells did not differ between $\mathrm{CKO}$ and WT animals at any time point examined (Fig. 2A-F,H). However, the number of CC1/Olig2double-positive mature oligodendrocytes was significantly decreased at P14 and P21 in the cortex of cKO animals compared with WT animals (Fig. 2I). Again, the number of mature oligodendrocytes in the Shp2 cKO animals returned to WT levels by P28 (Fig. 2C,F,I). Rare proliferating oligodendrocytes, as assessed by Ki67 and Sox10 double staining, were observed in both the cortex and corpus callosum of WT and cKO animals at P14 and P28 (data not shown). Together, these data suggest that the decreased number of oligodendrocytes in the cortex of Shp2 cKO animals resulted from a delay in oligodendrocyte differentiation, whereas there was little impact on the steadystate level of OPCs.

\section{Abnormal myelination in the Shp 2 cKO brain}

We next examined whether the conditional knockout of Shp2 from oligodendrocytes affected myelination in the corpus callosum. Western blots at P14 showed decreased levels in both MBP and PLP, two major protein components of the myelin membrane (Fig. 3A). Similarly, immunohistochemical staining against MOG showed decreased myelin protein at P14 in the corpus callosum and overlying motor cortex of cKO animals compared with WT animals (Fig. 3B). However, as with the number of oligodendrocytes, at P28, myelin protein levels were not different between cKO and WT littermates, as assessed by Western blot and immunohistochemistry (Fig. $3 A, B$ ).

To determine the effect of Shp $2 \mathrm{cKO}$ on individual myelinated axons, we assessed cKO and WT tissue using electron microscopy. At P14 and P28, we observed significantly fewer numbers of myelinated axons in the midline corpus callosum of cKO animals compared with WT (Fig. 3C-F,I). Furthermore, at P14 the thickness of myelin was not different in cKO corpus callosum compared with WT (Fig. 3C, E, G,J). Interestingly, at P28, while fewer axons were myelinated in $\mathrm{cKO}$ animals, the thickness of myelin on average was significantly greater in cKO compared with WT animals (Fig. $3 D, F, H, J$ ). The decreased g-ratios observed in $\mathrm{CKO}$ animals at P28 were consistent across all sizes of axons (Fig. $3 H$ ). These results suggest that myelination was delayed in the $\mathrm{cKO}$ brain and that, even when normal numbers of cells and amounts of myelin were achieved by $\mathrm{P} 28$, the number of axons that were myelinated was reduced. More intriguingly, the loss of Shp2 apparently also allowed myelinating oligodendrocytes to generate thicker myelin in cKO animals. This suggests that Shp2 could be important in regulating myelin sheath thickness during active myelin production.

Akt signaling through mTOR is an important driver of CNS myelination (Flores et al., 2008; Narayanan et al., 2009) and Shp2 is a known regulator of Akt signaling in cultured oligodendrocytes (Liu et al., 2011). Therefore, we examined major signaling pathways in the corpus callosum of Shp $2 \mathrm{cKO}$ and WT littermates. At P14 and P28, we observed no differences in the levels of phospho-Akt S473 or phospho-mTOR S2448 between WT and 
P14
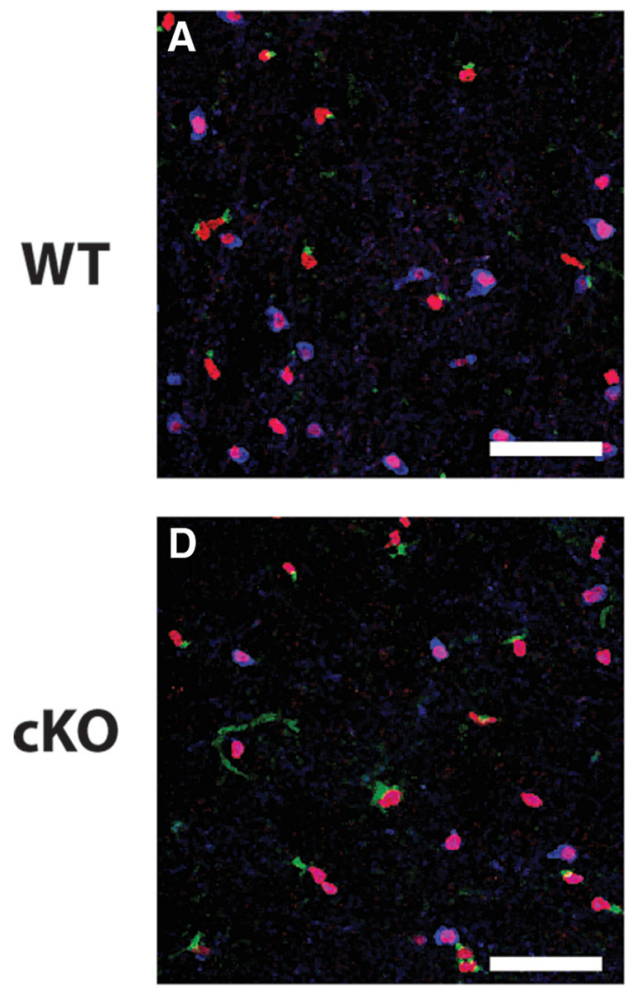

P21
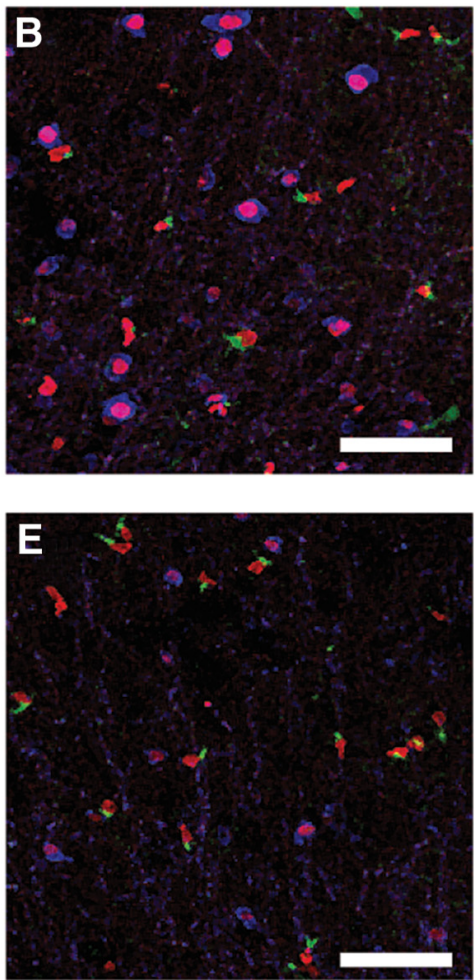

P28
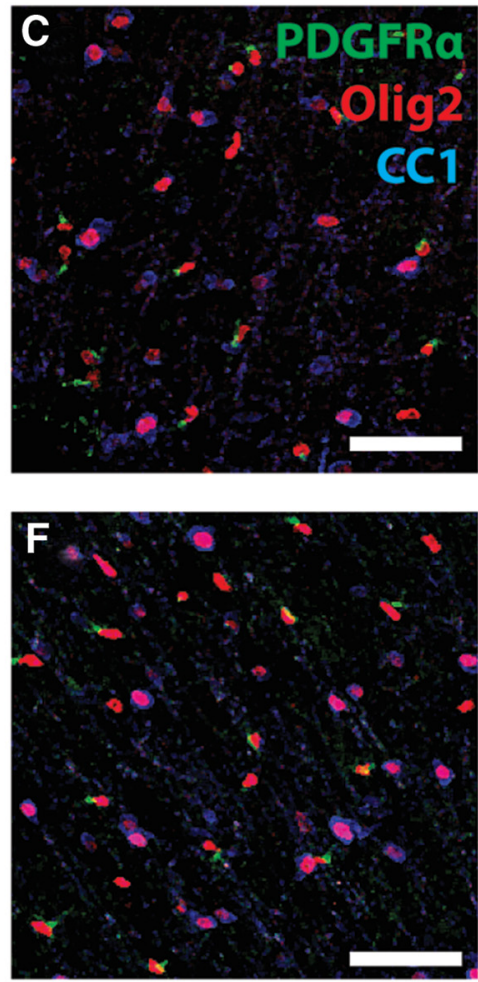

G

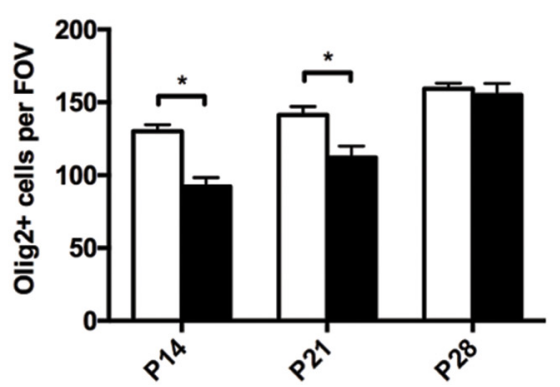

H

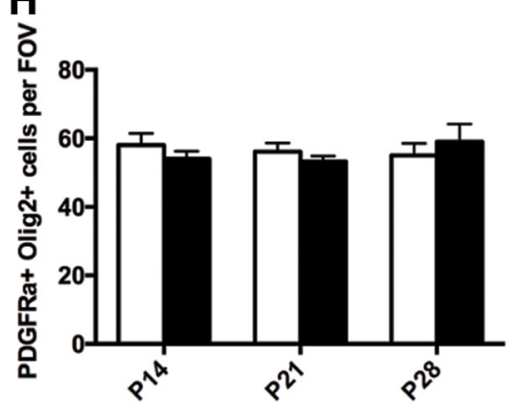

I

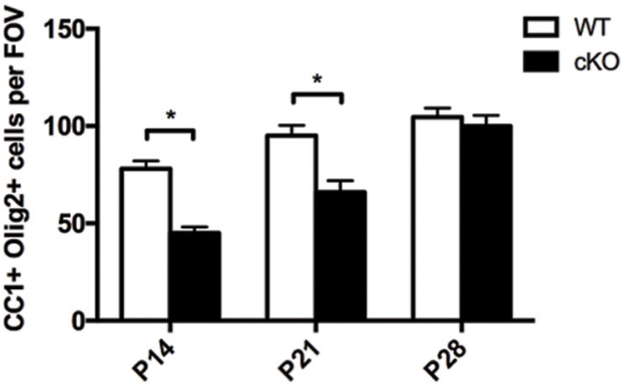

Figure 2. Delayed oligodendrocyte differentiation in the Shp2 cKO brain. $\boldsymbol{A}-\boldsymbol{F}, \mathrm{WT}(\boldsymbol{A}-\boldsymbol{C})$ and cKO (D-F) sections were immunostained to detect OPCs (PDGFR $\alpha$, green), total oligodendrocyte lineage cells (0lig2, red), and mature oligodendrocytes (CC1, blue) at P14, P21, and P28. G, Quantification of total oligodendrocyte lineage cells (0lig2 ${ }^{+}$) in WT (open bar) vs cK0 (dark bar) cortex. $\boldsymbol{H}$, Quantification of OPCs, identified by double staining with PDGFR $\alpha$ and Olig2. I, Quantification of mature oligodendrocytes, identified by double staining with CC1 and Olig2. White scale bars, $100 \mu \mathrm{m} . n=3$ animals/group. ${ }^{*} p<0.05$.

cKO animals (Fig. 4A-C). The ERK and FAK signaling pathways have also been shown to be important in regulating CNS myelination (Forrest et al., 2009; Ishii et al., 2012, 2013). At P14 and P28, we observed no difference in the level of phospho-ERK in the corpus callosum between WT and cKO (Fig. 4A-C). Similarly, no differences were noted in the levels of phospho-FAK signaling between $\mathrm{CKO}$ and WT animals at P14 (Fig. 4A,B). However, at P28, a dramatic and significant increase in the level of phospho-FAK was observed in cKO compared with WT animals $(197 \pm 22.5 \%$, relative to WT; Fig. $4 A, C)$. To determine the cellular location of increased pFAK expression, we performed IHC using antibodies against pFAK and oligodendrocyte-specific markers Sox10 and CC1. We observed increased pFAK expression that is localized to myelin processes of mature oligodendrocytes in the corpus callosum and striatum of cKO animals compared with WT animals (Fig. 4D). Thus, the increased myelin thickness seen in the P28 brains of cKO animals was not due to alterations in Akt/mTOR or ERK signaling, but did coincide with increased FAK signaling.

To determine whether there is a functional relationship between Shp2 and FAK in regulating myelination, we used a chemical inhibitor strategy in zebrafish embryos. Myelin is first detected in zebrafish spinal cord at $3 \mathrm{dpf}$ (Buckley et al., 2010). Therefore, we incubated embryos with chemical inhibitors from 2 to $4 \mathrm{dpf}$ to examine the early stages of myelination. Following exposure to $20 \mu \mathrm{M}$ PHPS1, a selective Shp2 inhibitor, we observed a significant increase in MBP protein expression by immunohistochemistry $(160.2 \pm 12.4 \%)$ and Western blot $(176.7 \pm 11.7 \%)$, compared with DMSO-treated controls (Fig. $5 A, B$ ). There was no difference in neurofilament-associated antigen (3A10) staining between treatment groups (Fig. 5A).

Since internode length is proportional to myelin sheath thickness (Hildebrand et al., 1993; Bechler et al., 2015), we investigated internode length in zebrafish. To assess the effects of Shp2 and FAK 


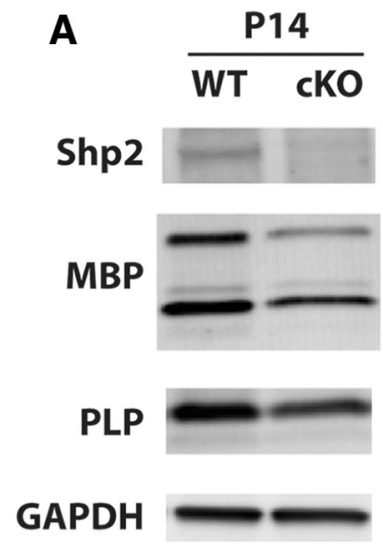

P14
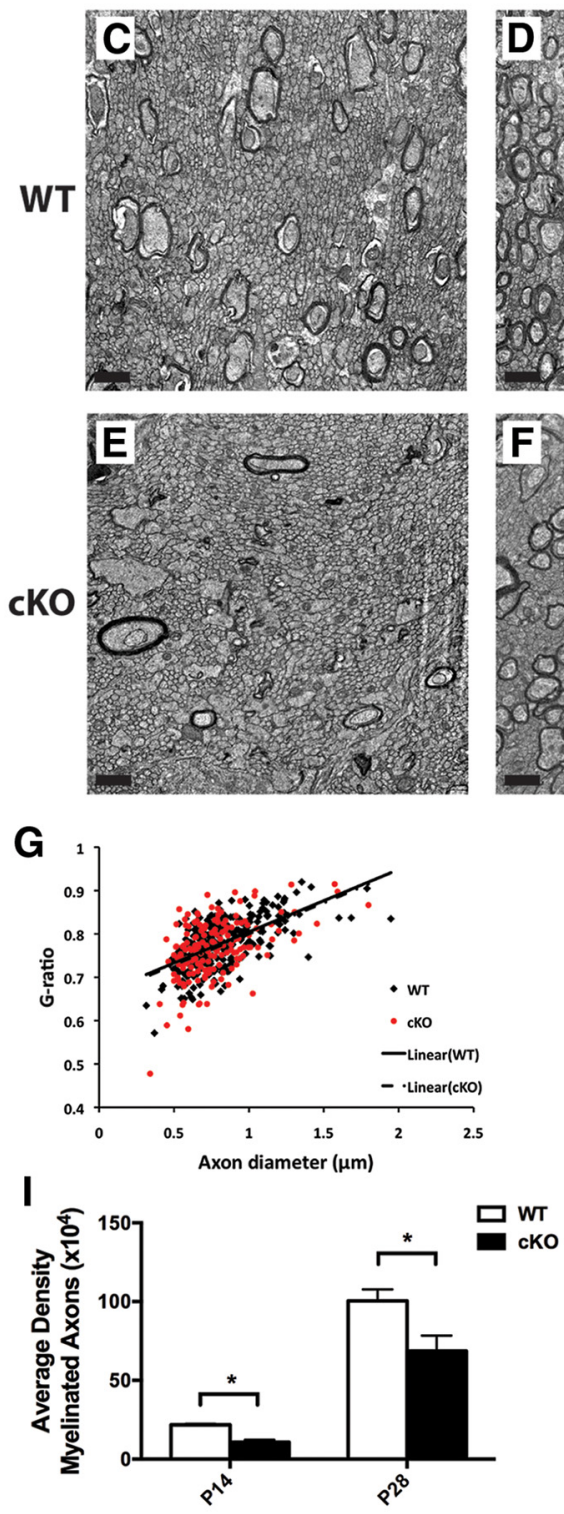
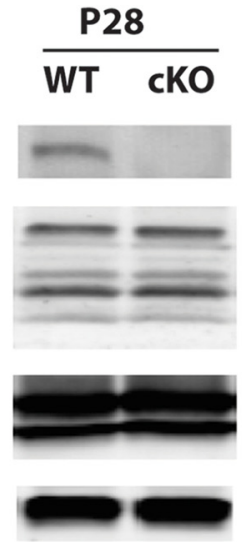

B

P14
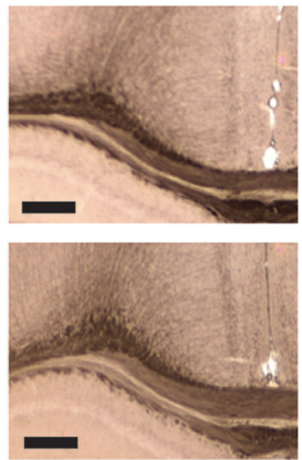

P28

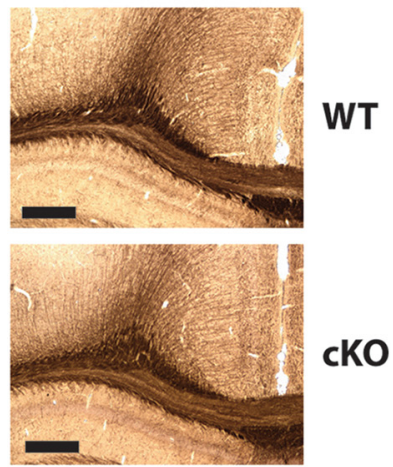

P28
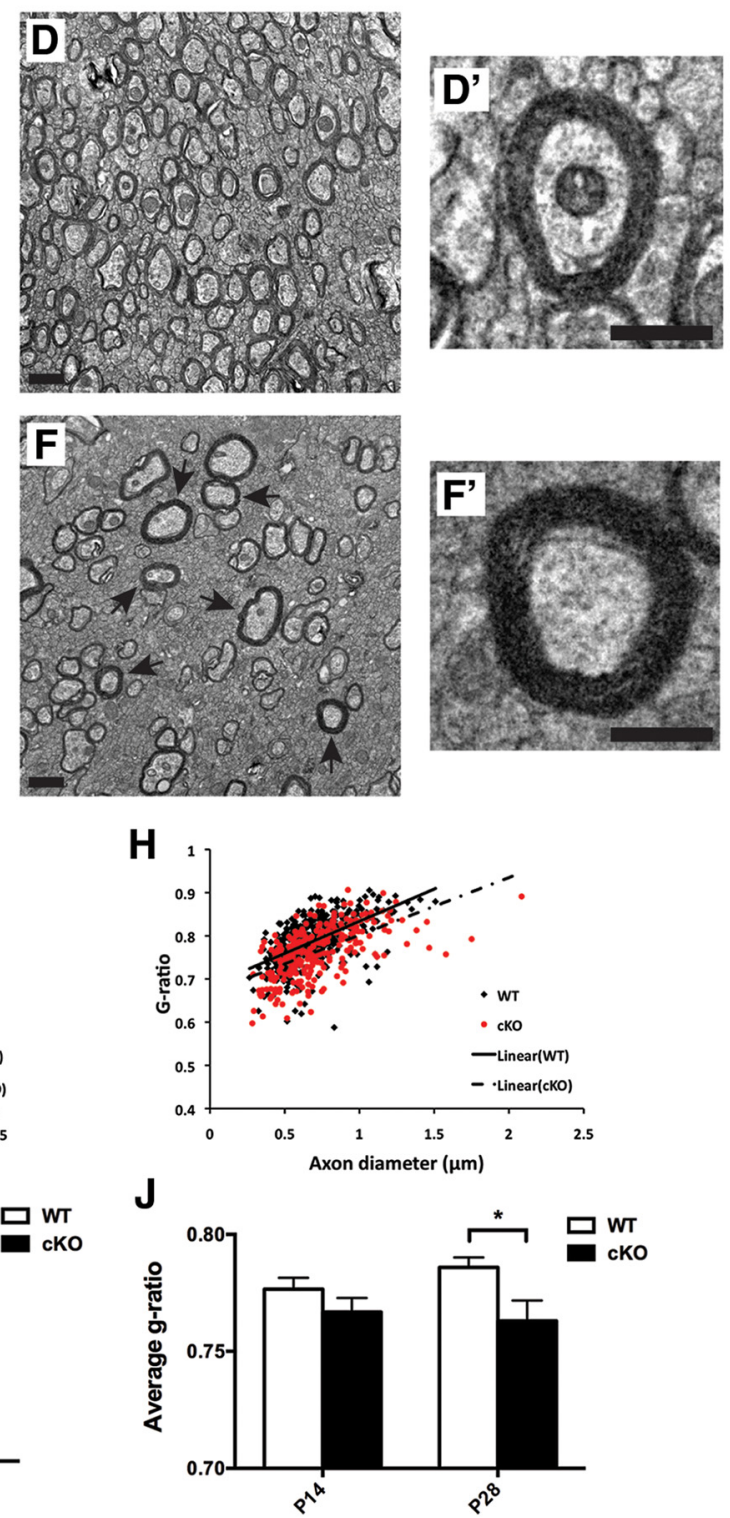

Figure 3. Abnormal myelination in the Shp2 cK0 brain. $A$, Representative Western blots from P14 (left) and P28 (right) corpus callosum lysates of WT and cK0 animals. $\boldsymbol{B}$, Representative coronal sections immunostained with MOG from P14 (left) and P28 (right) WT and cK0 animals. $\boldsymbol{C}-\boldsymbol{F}$, Representative electron micrographs from midline corpus callosum of WT (C, D) and cKO (E, $\boldsymbol{F}$ ) animals at P14 and P28. $\boldsymbol{D}^{\prime}, \boldsymbol{F}^{\prime}$, High-magnification images of individual myelinated axons in WT and cK0 animals. $\mathbf{G}, \boldsymbol{H}$, Scatter plots of axon diameter vs g-ratio for individual myelinated axons from WT (black dots, solid line) and cKO (red dots, dashed line) animals at P14 $(\boldsymbol{G})$ and P28 (H). $\boldsymbol{I}, \boldsymbol{J}$, Quantification of average density of myelinated axons per square millimeter $(\boldsymbol{I})$ and average g-ratio $(\boldsymbol{J})$ in WT and cKO corpus callosum. Scale bars: $\boldsymbol{B}, 250 \mu \mathrm{m} ; \boldsymbol{C}-\boldsymbol{F}, 1 \mu \mathrm{m} ; \boldsymbol{D}^{\prime}, \boldsymbol{F}^{\prime}, 500 \mathrm{~nm} . n=3$ animals/group. ${ }^{*} p<0.05$. 
A

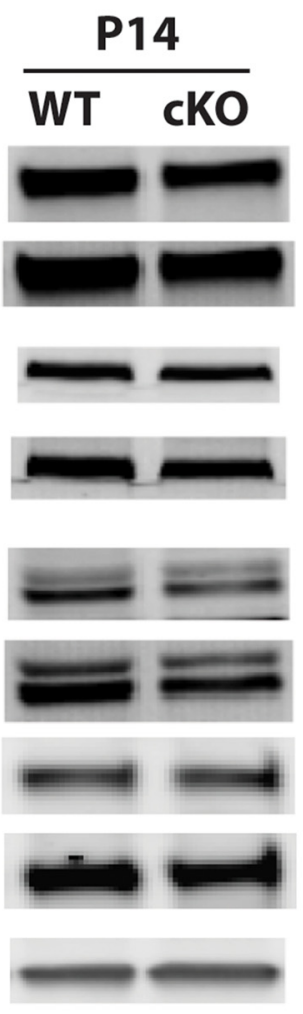

P28
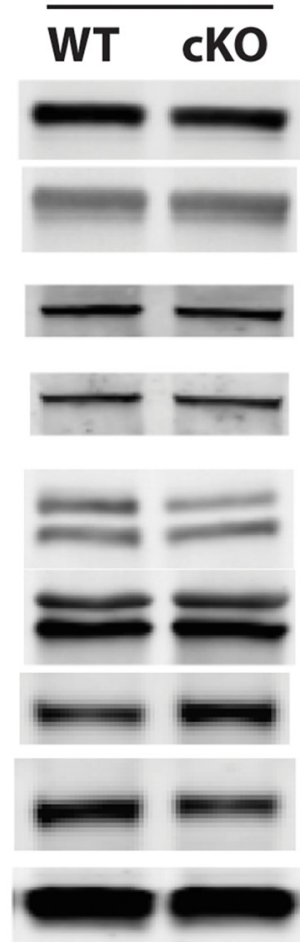

p-Akt S473

Total Akt

p-mTOR S2448

Total mTOR

p-ERK1/2

Total ERK1/2

p-FAK Y397

FAK

GAPDH
B

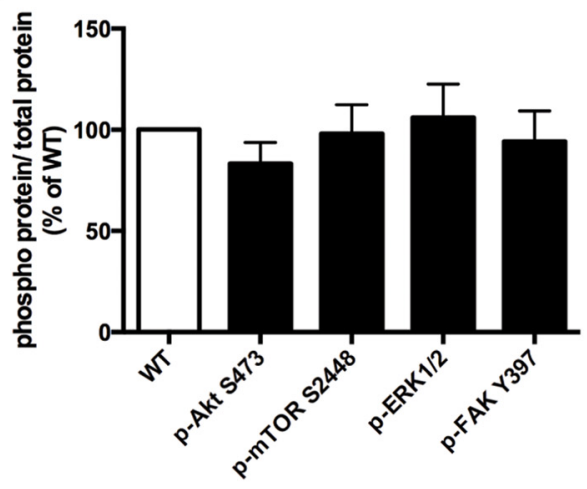

C

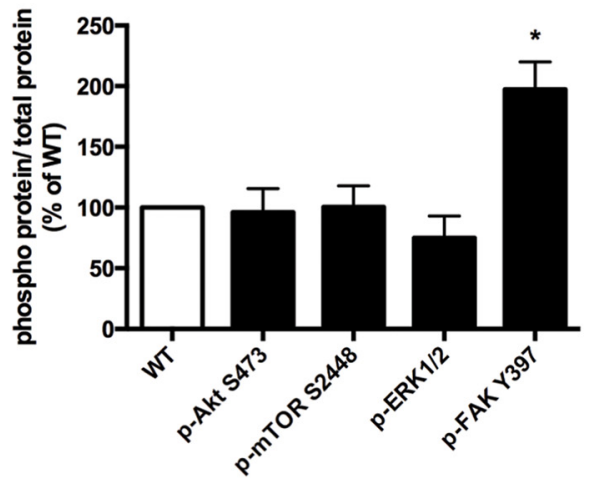

D Corpus callosum
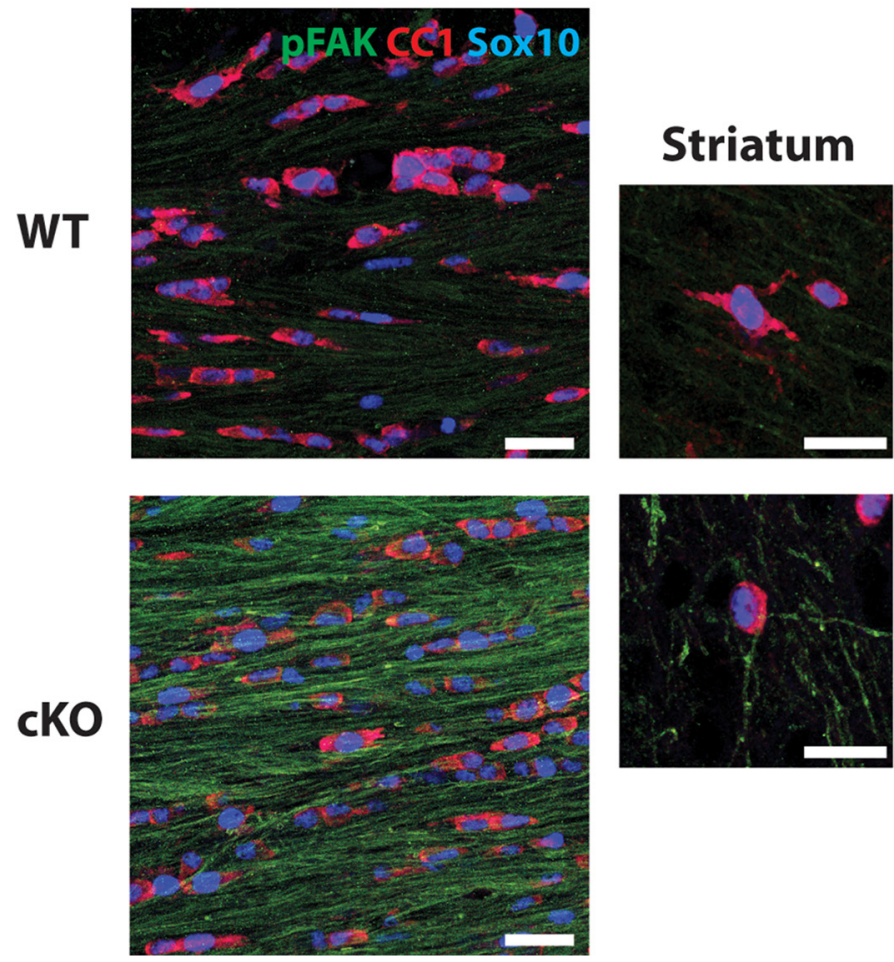

Figure 4. FAK signaling, not Akt/mTOR or ERK signaling, altered in Shp2 cKO corpus callosum. $A$, Representative Western blots from P14 (left) and P28 (right) corpus callosum lysates of WT and cKO animals. Four independent Western blots were run, corresponding to each of four independent sets of experimental animals $(n=4)$. $B, C$, Quantification of signaling data indicated that little change was noted at P14 (B), but by P28 there was a significant increase in phospho-FAK signaling ( $\boldsymbol{C}$. Quantification performed using 0dyssey software and phospho-signaling was evaluated relative to total protein. For each signaling component, $\mathrm{CKO}$ values are displayed as a percentage of WT (set to 100). ${ }^{*} p<0.05$. D, Immunohistochemical analysis of phospho-FAK Y392 (green) expression at P29 in WT and cK0 oligodendrocytes [CC1 (red) and Sox 10 (blue)-double-positive cells] from the corpus callosum and striatum. Scale bars: Corpus callosum, $25 \mu \mathrm{m}$; striatum, $20 \mu \mathrm{m}$. 
A

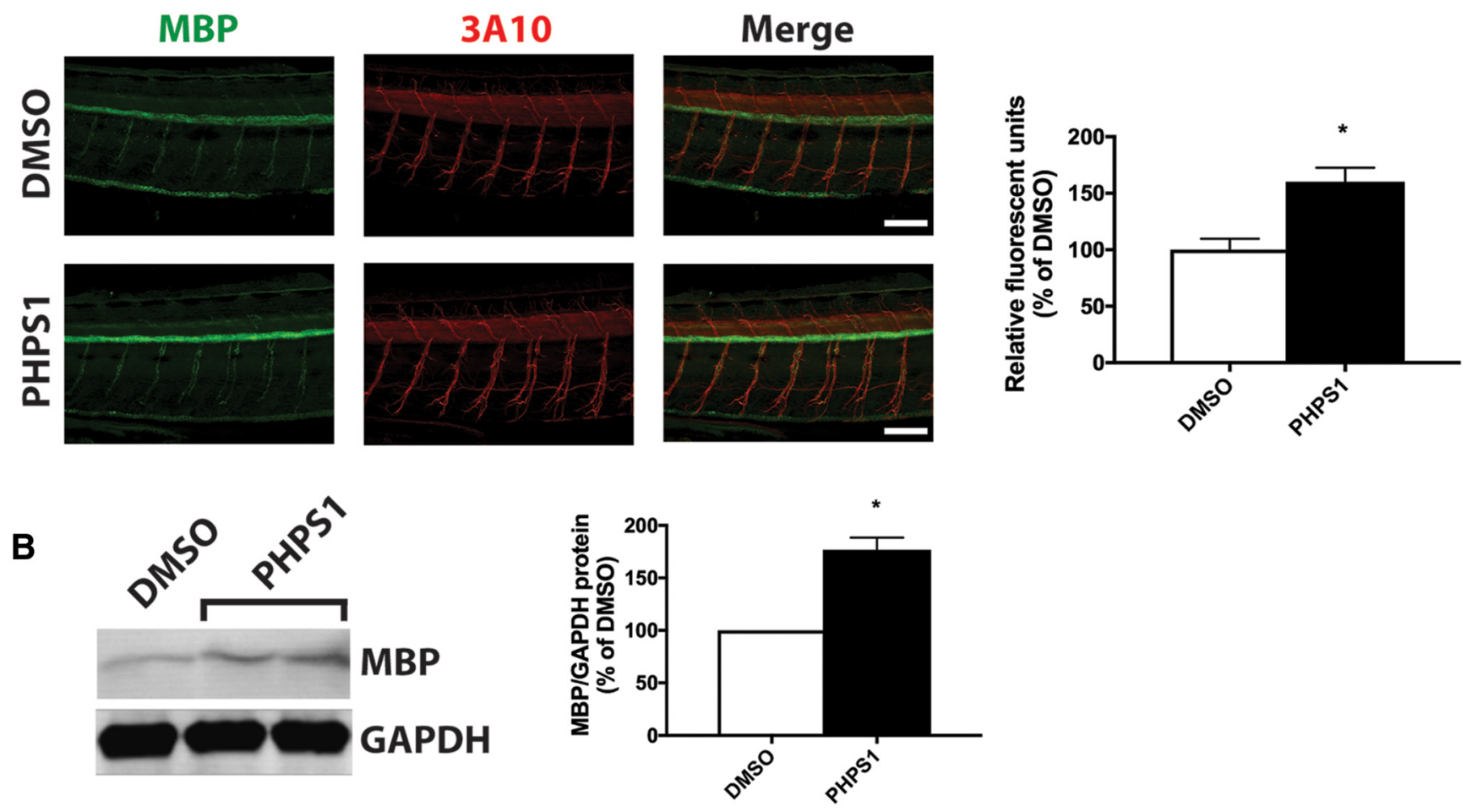

C
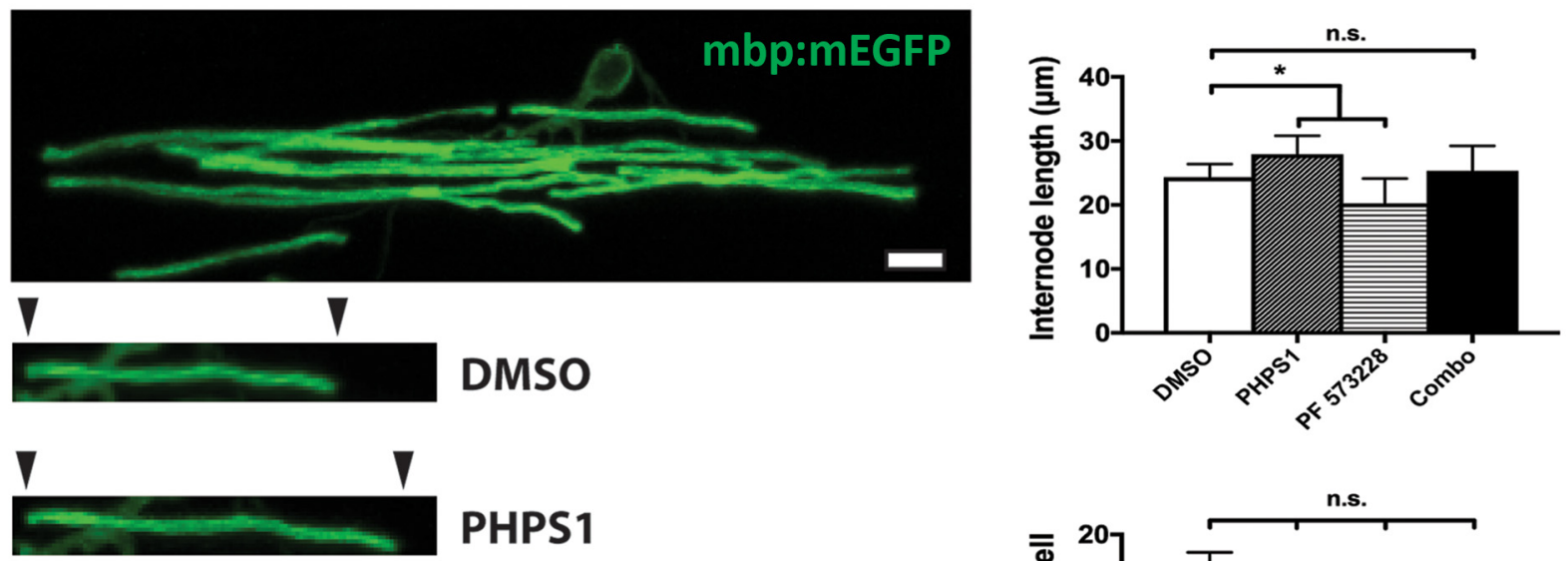

PHPS1

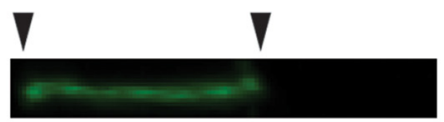

PF 573228
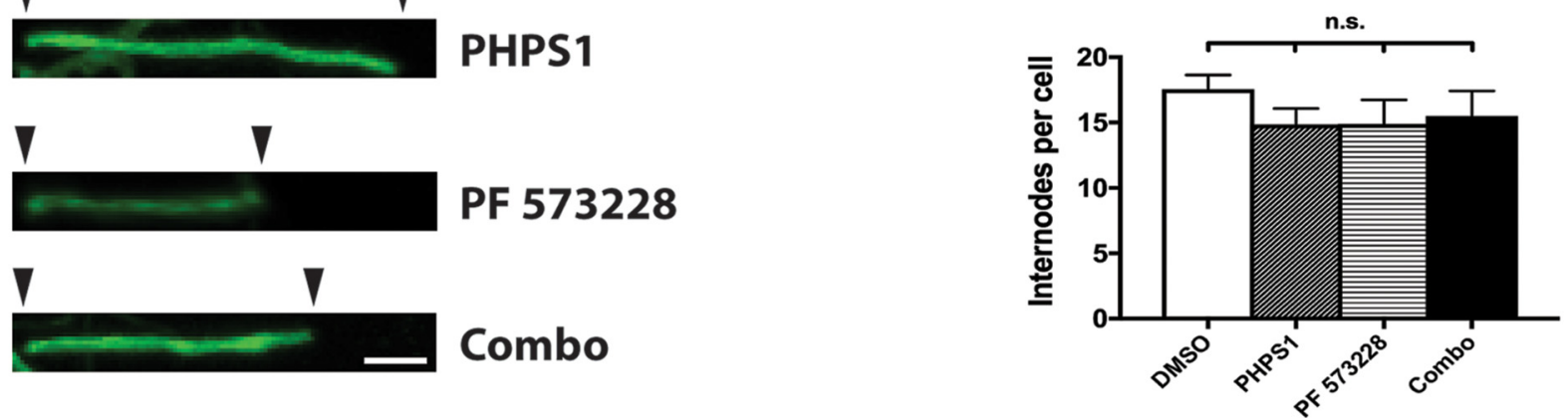

Figure 5. Shp2 and FAK interact to regulate myelin internode length. Zebrafish embryos were treated from 2 to 4 dpf with DMSO, PHPS1 (Shp2 inhibitor), and/or PF 573228 (FAK inhibitor). $\boldsymbol{A}$, Whole-mount immunohistochemical analysis of MBP (green) and neurofilament-associated antigen (red) expression. Scale bars, $100 \mu \mathrm{m}$. $\boldsymbol{B}$, Representative Western blots from whole zebrafish (two independent PHPS1-treated samples are shown) and quantified. C, The length and number of internodes from individual oligodendrocytes expressing mbp-mEGFP in mosaic zebrafish were analyzed after chemical exposure. Scale bars: representative full cell, $10 \mu \mathrm{m}$; images of individual internodes, $5 \mu \mathrm{m}$. At least three independent inhibitor experiments were done for each analysis. For internode analyses, at least 10 cells were analyzed from each group. ${ }^{*} p$ value $<0.05$.

inhibition on internode length, zebrafish embryos were injected with pEXPRESS-mbp:mEGFP.pA.cmcl2:RFP.tol2 plasmids and cappedtol 2 mRNA at the one-cell stage. This allowed for mosaic expression of EGFP in a subset of oligodendrocytes so that the internodes of individual cells could be quantified. Zebrafish embryos were treated with DMSO or PHPS1 from 48 to $96 \mathrm{hpf}$ and analyzed at 96 hpf. Consistent with MBP IHC and Western blot data in Figure $5 A$, we observed significantly longer internodes in zebrafish 
embryos after chemical inhibition of Shp2 compared with DMSOtreated controls (Fig. 5C). We next used the FAK inhibitor PF 573228 alone or in combination with PHPS1. FAK inhibition alone was sufficient to cause a significant decrease in internode length compared with DMSO control (Fig. 5C), which is consistent with previous studies examining the role of FAK during myelination (Forrest et al., 2009; Lafrenaye and Fuss, 2010). Interestingly, the combination exposure of PHPS1 with PF 573228 rescued the increased internode length seen with PHPS1 exposure alone (Fig. 5C). These results suggest that Shp 2 and FAK act cooperatively to regulate early stages of CNS myelination.

\section{Oligodendrocyte Shp2 is not necessary for long-term maintenance of myelination}

The developmental impact of Shp2 loss suggested that Shp2 could be involved in regulating myelin production in actively myelinating oligodendrocytes. To address this question more directly, without the confounding effects of Shp 2 function during early oligodendrocyte generation and differentiation, we used the tamoxifeninducible form of Cre-recombinase driven in oligodendrocyte lineage cells by the PLP promotor (PLP-CreERT). The floxed Shp2 alleles were crossed into the PLP-CreERT line to generate $P L P^{\text {creERT/+}} ; S h p 2^{f l f l}$ animals (tamoxifen-treated animals referred to as icKO, vehicle-treated animals referred to as Veh Con) and $P L P^{+/+} ; S h p 2^{f l f l}$ animals (treated with tamoxifen and referred to as Tam Con). To examine the role of Shp2 during active myelination, tamoxifen or vehicle was administered once per day for $10 \mathrm{~d}$ starting at P25, and animals were killed 6 or 12 weeks after the final injection. Animals were analyzed for myelin changes by Western blot 12 weeks after the final injection. In the corpus callosum of Shp2 icKO animals, Shp2 levels were barely detectable by Western blot but were unchanged for both Veh Con and Tam Con animals, thereby verifying the efficiency of recombination (Fig. 6A). No changes were observed in icKO compared with controls in the level of any of the major myelin proteins, including myelin-associated glycoprotein (MAG), MBP, and PLP (Fig. 6A). Similarly, there were no differences observed in MOG immunostaining in icKO animals compared with control groups at 6 or 12 weeks after injections (Fig. $6 B$ ). There were also no differences in the density of myelinated axons, average g-ratio, or myelin ultrastructure in icKO brains compared with controls, as assessed by electron microscopy (Fig. 6C, left column, D).

To assess whether Shp2 was involved in maintaining myelin after active developmental myelin production had ceased, tamoxifen or vehicle was administered once per day for $10 \mathrm{~d}$ starting at P85. Animals were killed 6 weeks after the final injection. Again, no differences were observed in MOG immunostaining in icKO brains compared with controls (Fig. $6 B$, right column). Similarly, no differences were observed in the density of myelinated axons, average g-ratio, or myelin ultrastructure in icKO brains compared with controls (Fig. 6C, right column, D).

\section{Oligodendrocyte Shp2 regulates timely differentiation following lysolecithin-induced demyelination}

Remyelination is the process of regenerating myelin after a demyelinating injury and is considered one of the most robust regenerative processes in the adult brain (Franklin and FfrenchConstant, 2008). Many aspects of developmental myelination are conserved in the remyelination process (Fancy et al., 2011). The data presented above suggest that Shp2 is an important regulator of oligodendrocyte differentiation and early stages of myelination during development. Therefore, we hypothesized that Shp2 could regulate OPC differentiation to promote remyelination after a demyelination injury.

Demyelination was induced by focal injection of lysolecithin into the dorsal white matter of the thoracic spinal cord. Shp2 knockout was induced in oligodendrocytes by daily tamoxifen treatment, starting at $3 \mathrm{dpl}$ and continuing for $7 \mathrm{~d}$. Tamoxifen injection after lesion was necessary because recombination was driven by the PLP promoter. Thus, injection before lesion would delete Shp2 in myelinating oligodendrocytes, which would be lost after lysolecithin treatment, and remyelination would occur by cells differentiating from OPCs that were not recombined. By inducing recombination after lesion, cells that were in the process of differentiating were induced to delete Shp2. Animals were analyzed at $14 \mathrm{dpl}$ (when new oligodendrocytes differentiate in the demyelinated lesion), $21 \mathrm{dpl}$ (when active remyelination occurs), and $35 \mathrm{dpl}$ (when remyelination is normally complete; Jeffery and Blakemore, 1995).

First, we confirmed efficient knockout of Shp2 from oligodendrocytes in the demyelinated/remyelinated lesions (Fig. 7). The majority of Sox10-positive cells also expressed Shp2 in the dorsal column of Veh Con $(85.8 \pm 4.7 \%)$ and Tam Con $(88.2 \pm 3.5 \%)$ animals, whereas only $12.8 \pm 4.9 \%$ of Sox 10 -positive cells also expressed Shp2 in icKO animals (Fig. $7 A-C, J$ ). At $21 \mathrm{dpl},>80 \%$ of Sox10-positive cells also expressed Shp2 in control groups $(84.8 \pm 4.8 \%$ and $83.9 \pm 5.1 \%$ in Veh Con and Tam Con groups, respectively), whereas only $21.4 \pm 5.6 \%$ of Sox 10 -positive cells expressed Shp2 in icKO animals (Fig. 7D-F,J). Again, at $35 \mathrm{dpl}$, $>80 \%$ of Sox 10-positive cells expressed Shp2 in control groups $(80.7 \pm 6.2 \%$ and $82.3 \pm 4.4 \%$ in Veh Con and Tam Con groups, respectively), whereas only $24.4 \pm 6.8 \%$ of Sox 10 -positive cells expressed Shp2 in icKO animals (Fig. $7 G-J$ ). Thus, Shp2 was effectively deleted from the majority of oligodendrocytes in the icKO dorsal column compared with control groups.

Next, we assessed oligodendrocyte recruitment and remyelination by immunostaining with Olig2 and MBP, respectively. At $14 \mathrm{dpl}$, significantly fewer Olig2-positive cells were present in the dorsal column of icKO mice compared with Veh Con and Tam Con groups $\left(1301 \pm 51,1777 \pm 164\right.$, and $1844 \pm 86$ cells $/ \mathrm{mm}^{2}$, respectively; Fig. $8 A-C, J)$. At $21 \mathrm{dpl}$, there was no difference in the number of Olig2-positive cells in the dorsal column of icKO compared with Veh Con and Tam Con animals (1690 \pm 98, $1821 \pm 182$, and $1795 \pm 115$ cells $/ \mathrm{mm}^{2}$, respectively; Fig. $\left.8 D-F, J\right)$. Similarly, at $35 \mathrm{dpl}$, there was also no difference in the number of Olig2-positive cells in the dorsal column of icKO animals compared with Veh Con and Tam Con animals $(1861 \pm 74,1818 \pm 109$, and $1854 \pm 151$ cells $/ \mathrm{mm}^{2}$, respectively; Fig. $\left.8 G-J\right)$. Thus, without oligodendrocyte Shp2, there was a delay in oligodendrocyte recruitment to the demyelinated lesion at $14 \mathrm{dpl}$, which recovered by $21 \mathrm{dpl}$.

To quantify the amount of remyelination in the lesioned spinal cord, we measured the percentage of the area of the dorsal column that was stained by MBP. At $14 \mathrm{dpl}$, we observed equivalent MBP coverage in the dorsal column in Veh Con, Tam Con, and icKO $(35.2 \pm 3.3 \%, 35.2 \pm 3.4 \%$, and $36.2 \pm 3.8 \%$, respectively), suggesting equivalent demyelination between groups (Fig. 8A-C,K). At $21 \mathrm{dpl}$, however, the icKO animals had significantly less MBP coverage compared with Veh Con and Tam Con $(44.2 \pm 3.5 \%, 61.3 \pm 2.0 \%$, and $61.6 \pm 2.7 \%$, respectively; Fig. $8 D-F, K)$. By $35 \mathrm{dpl}$, the MBP coverage was not significantly different among Veh Con, Tam Con, and icKO groups (78.7 \pm $4.0 \%, 63.8 \pm 2.9 \%$, and $73.1 \pm 4.4 \%$, respectively; Fig. $8 G-I, K)$. Together, these results suggest that the induced knockout of Shp2 from oligodendrocytes following lysolecithin demyelination 
A

$$
\text { P25-34 } \rightarrow 12 \text { wks }
$$

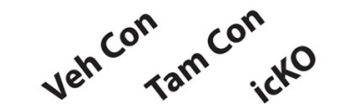

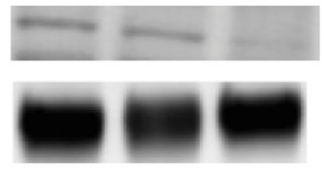

Shp2

MAG
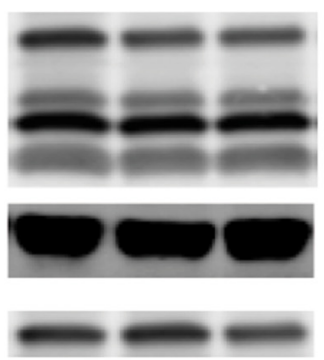

MBP

PLP

GAPDH

B
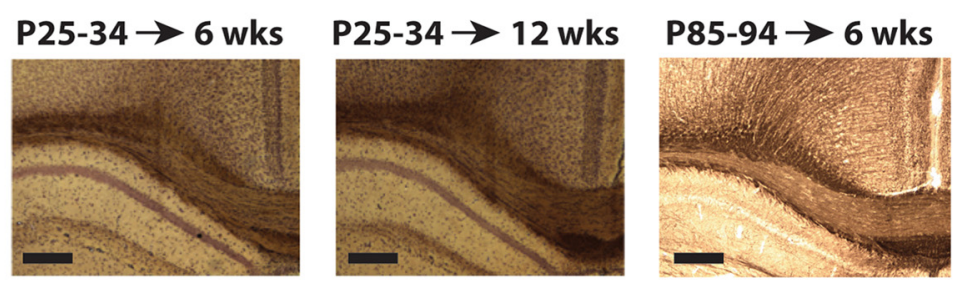

Veh Con
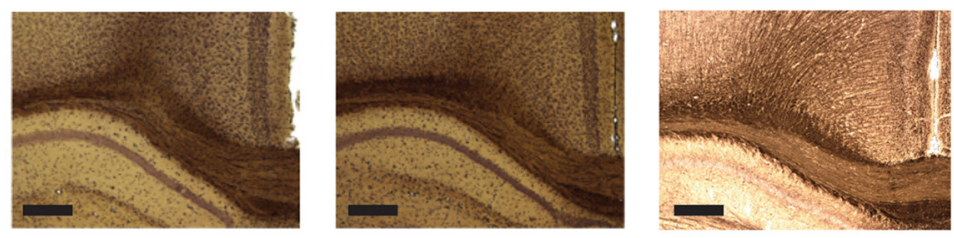

Tam Con
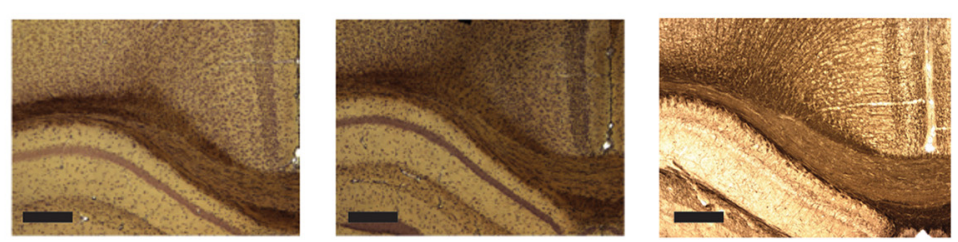

icKO

\section{C}
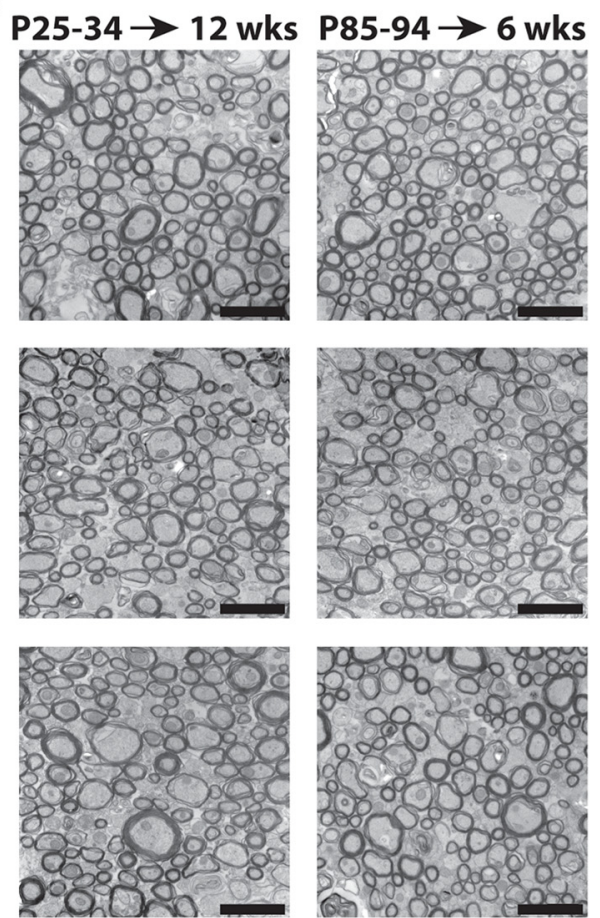

Veh Con

D

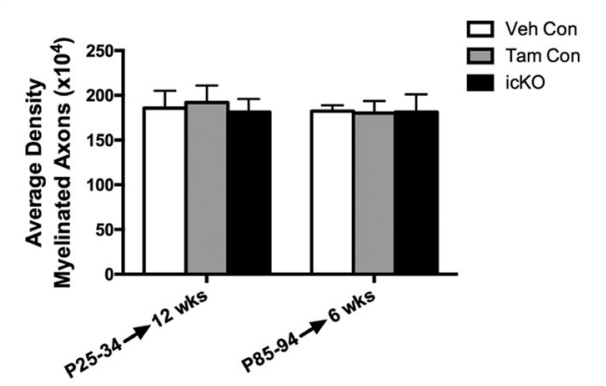

Tam Con

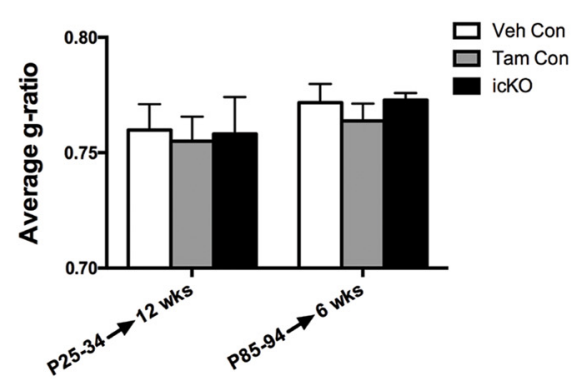

Figure 6. Oligodendrocyte Shp2 is not necessary for long-term maintenance of myelination. $\boldsymbol{A}$, Representative myelin Western blots of corpus callosum lysates from PLPcreERT;Shp2fl/fl mice samples, Veh Con (left), Tam Con (middle), and icKO (right) animals collected 12 weeks after Shp2 conditional knockout induced at $\sim 1$ month of age. $\boldsymbol{B}$, Representative MOG immunostaining from corpus callosum of Veh Con (top row), Tam Con (middle row), and icK0 (bottom row) after Shp2-induced knockout. Knockout was induced at $\sim 1$ month of age, and animals were analyzed 6 or 12 weeks later (left and middle columns, respectively) or was induced at $\sim 3$ months of age and analyzed 6 weeks later (right column). C, Representative electron micrographs from midline corpus callosum of Veh Con, Tam Con, and icK0 animals. Left column, Tamoxifen injected at P25-P34 and analyzed 12 weeks later. Right column, Tamoxifen injected at P85-P94 and analyzed 6 weeks later. D, Quantification of average density of myelinated axons (per square millimeter) and average g-ratio in Veh Con, Tam Con, and ick0 corpus callosum. Scale bars: $\boldsymbol{B}, 250 \mu \mathrm{m} ; \boldsymbol{C}, 2 \mu \mathrm{m} . n=3$ animals/group.

caused an initial delay in the recruitment of oligodendrocytes to the demyelinated lesion, resulting in delayed remyelination, but that remyelination approached normal levels within $35 \mathrm{~d}$.

Finally, we assessed whether the oligodendrocyte differentiation delay observed in Shp2 cKO animals during development (Fig. 2) was recapitulated during remyelination. At $14 \mathrm{dpl}$, significantly fewer differentiated oligodendrocytes ( $\mathrm{CC} 1 /$ Sox10-double-positive cells) were present in the dorsal column of icKO mice compared with
Veh Con and Tam Con groups ( $562 \pm 80,960 \pm 137$, and $1019 \pm$ 68 cells $/ \mathrm{mm}^{2}$, respectively; Fig. $\left.9 A-C, J\right)$. This reduction in differentiated oligodendrocytes persisted until $21 \mathrm{dpl}(1295 \pm 118$, $1229 \pm 83$, and $721 \pm 133$ cells $/ \mathrm{mm}^{2}$ in Veh Con, Tam Con, and icKO groups, respectively; Fig. 9D-F,J). By 35 dpl, oligodendrocyte differentiation caught up to control groups, and there was no difference in the density of CC1/Sox10-double-positive cells in the dorsal column of icKO animals compared with Veh Con and 

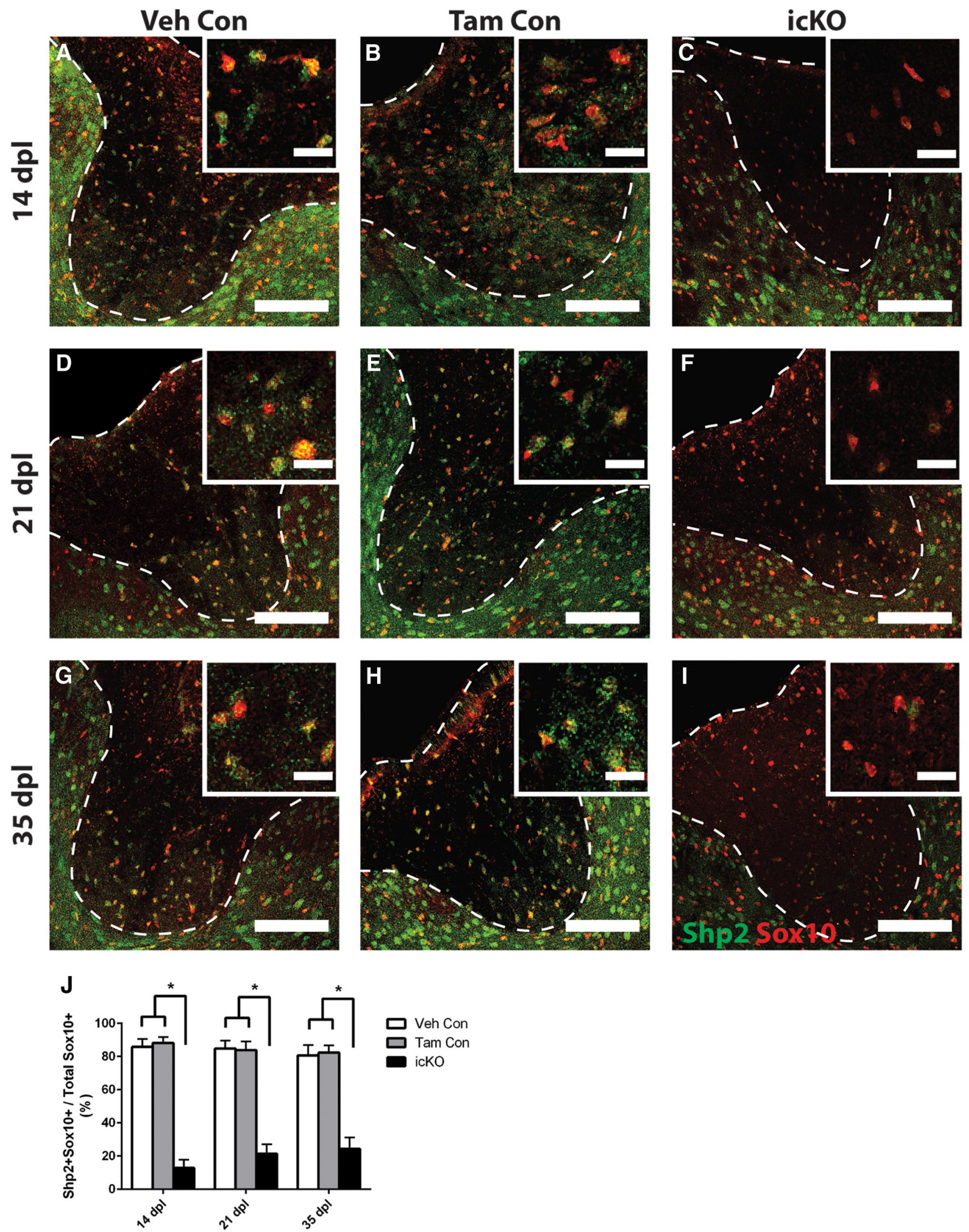

Figure 7. Efficient knockout of Shp2 from oligodendrocytes in the spinal cord after lysolecithin-induced demyelination. $A-I$, Representative spinal cord sections from Veh Con, Tam Con, and ick0 were immunostained with Shp2 (green) and Sox10 (red) at $14 \mathrm{dpl}(\boldsymbol{A}-\boldsymbol{C}), 21 \mathrm{dpl}(\boldsymbol{D}-\boldsymbol{F})$, and $35 \mathrm{dpl}(\mathbf{G}-\mathbf{I})$.J, Quantification of colocalization of Shp2 with Sox 10. Scale bars, $25 \mu \mathrm{m}$; inset $1 \mu \mathrm{m} . n=$ 3 animals/group. ${ }^{*} p<0.05$. 

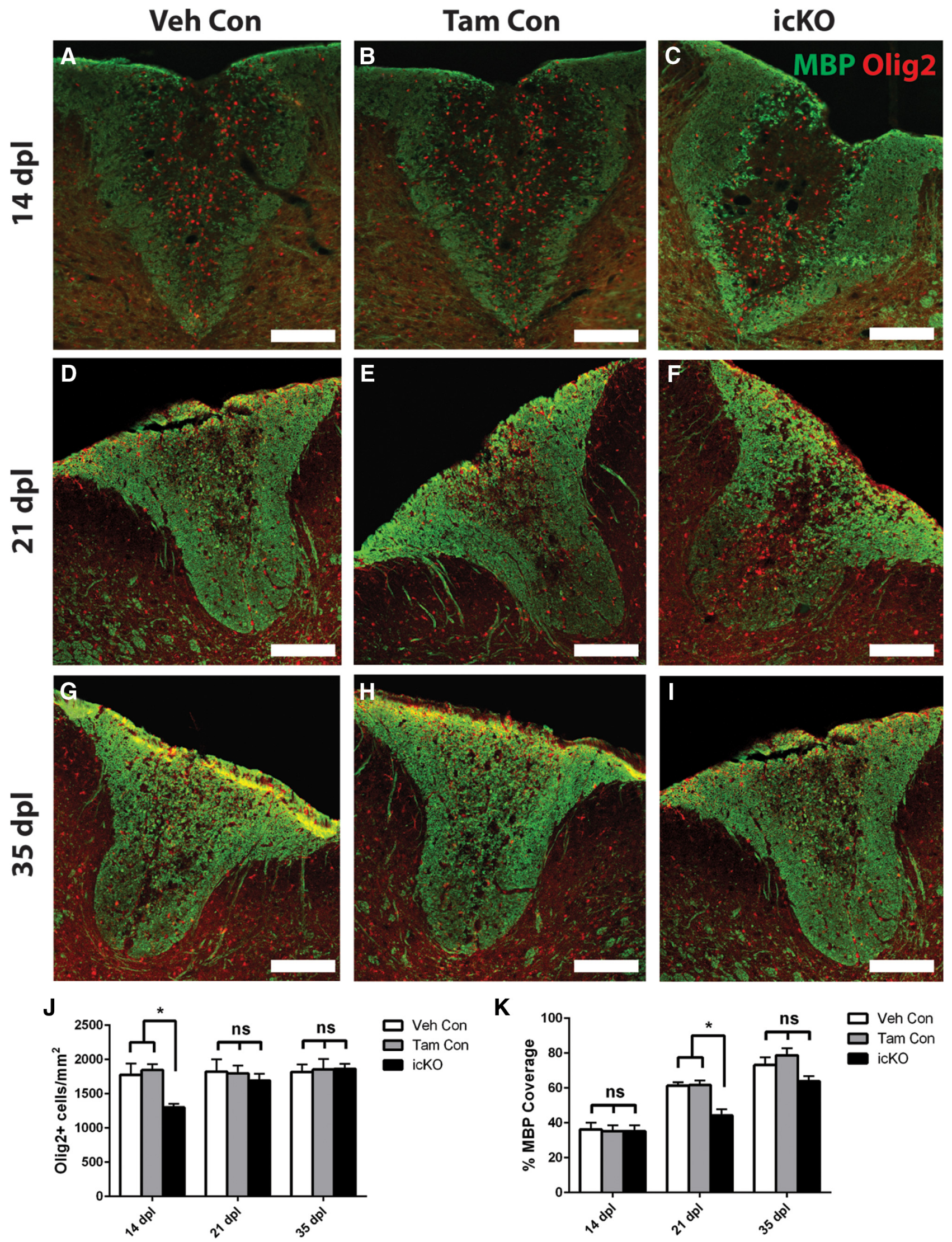

Figure 8. Delayed oligodendrocyte recruitment and remyelination in icK0 spinal cord. $A-I$, Representative spinal cord sections from Veh Con, Tam Con, and icK0 animals were immunostained with MBP (green) and Olig2 (red) at $14 \mathrm{dpl}(\boldsymbol{A}-\boldsymbol{C}), 21 \mathrm{dpl}(\boldsymbol{D}-\boldsymbol{F})$, and $35 \mathrm{dpl}(\mathbf{G}-\boldsymbol{I})$. J, Quantification of the number of Olig2-positive oligodendrocytes in the injured dorsal column. $\boldsymbol{K}$, Quantification of MBP immunostaining as a percentage of total dorsal column area. Scale bars, $100 \mu \mathrm{m} . n=3$ animals/group. ${ }^{*} p<0.05$. 

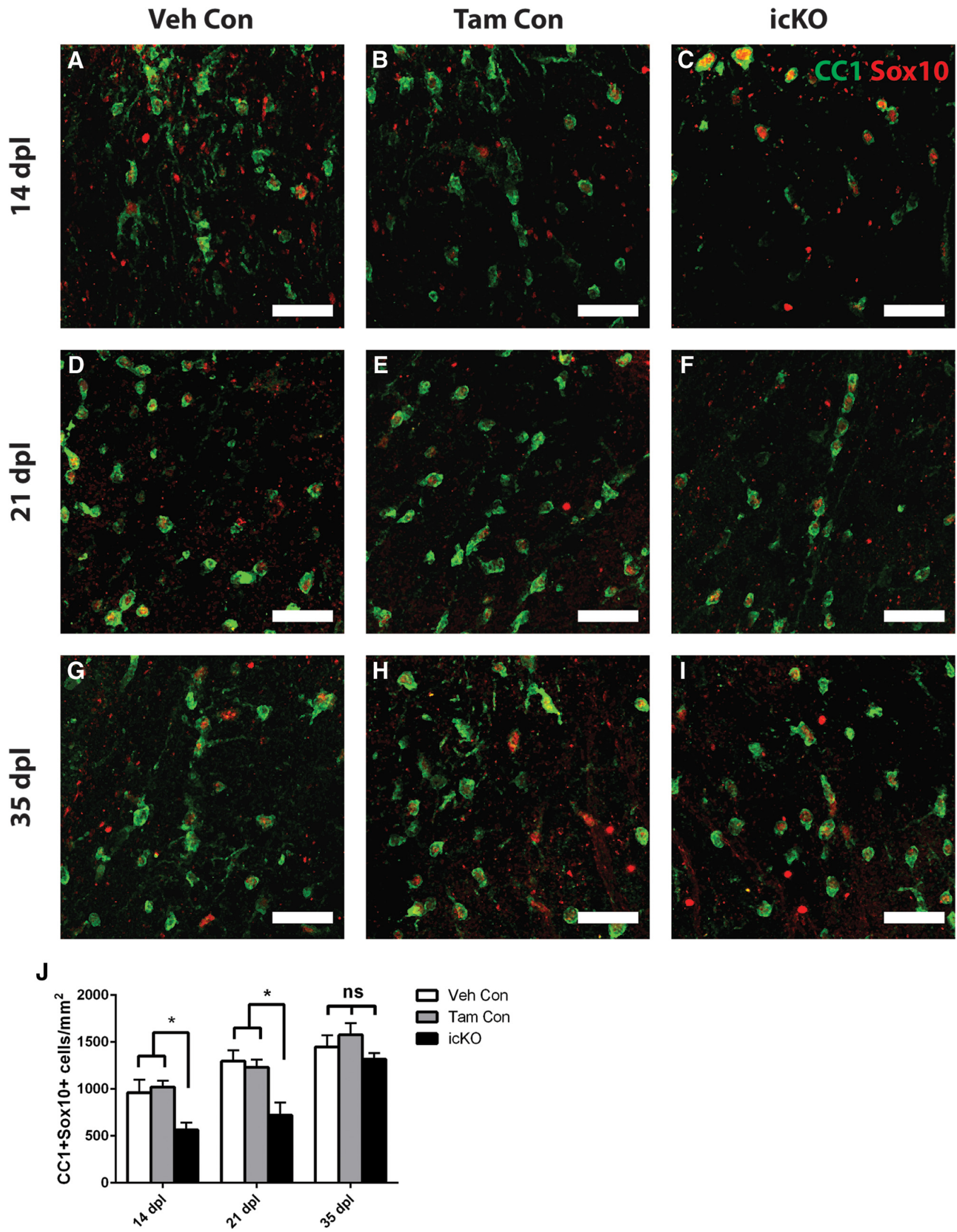

Figure 9. Delayed differentiation of remyelinating oligodendrocytes in Shp2 icK0 spinal cord. $A-I$, Representative spinal cord sections from Veh Con, Tam Con, and ick0 were immunostained with CC1 (green) and Sox10 (red) at $14 \mathrm{dpl}(\boldsymbol{A}-\boldsymbol{C}), 21 \mathrm{dpl}(\mathbf{D}-\boldsymbol{F})$, and $35 \mathrm{dpl}(\mathbf{G}-\mathbf{I})$. J, Quantification of differentiated oligodendrocytes (CC1, Sox10-double-positive immunostaining) in the injured dorsal column. Scale bars: panels, $25 \mu \mathrm{m}$; insets, $1 \mu \mathrm{m} . n=3$ animals/group. ${ }^{*} p<0.05$. 
Tam Con animals $(1316 \pm 66,1447 \pm 124$, and $1576 \pm 125$ cells $/ \mathrm{mm}^{2}$, respectively; Fig. $9 G-J$ ). Thus, without Shp2 expression in oligodendrocytes, there was a delay in oligodendrocyte recruitment to, and differentiation in, the demyelinated lesion at $14 \mathrm{dpl}$, which recovered by $21 \mathrm{dpl}$. Together, these results suggest that oligodendrocyte Shp2 influences remyelination in the spinal cord by promoting timely oligodendrocyte recruitment and differentiation.

\section{Discussion}

In the current study, using in vivo conditional and inducible knockout mouse models and chemical inhibitor treatment of zebrafish, we present three primary findings regarding the function of Shp2 in oligodendrocytes. First, we verified previous reports suggesting a role of Shp2 in regulating oligodendrocyte differentiation during development using a different transgenic Cre mouse line (Zhu et al., 2010; Fig. 2). Second, we showed that Shp2 may act as a negative regulator during active CNS myelination and that these effects may be mediated through Shp2 inhibition of FAK signaling. Additionally, Shp2 is dispensable for long-term myelin maintenance when deleted after myelination is complete. Third, we showed that oligodendrocyte Shp2 was necessary for timely remyelination following lysolecithininduced demyelination by influencing oligodendrocyte recruitment and differentiation.

Early studies on the effect of Shp2 on oligodendrocyte differentiation in cultured oligodendrocytes resulted in inconsistent conclusions. One study demonstrated that Shp2 promoted maturation of oligodendrocytes (Liu et al., 2011), while the other concluded that Shp2 inhibited maturation and maintained OPCs in a proliferative state (Kuo et al., 2010). Subtle differences in experimental procedures likely explain the differences between these two reports. Using in vivo studies, Zhu et al. (2010) used the Olig1-Cre mouse to delete Shp2 from oligodendrocytes and were able to show that in addition to regulating oligodendrocyte generation in the developing spinal cord, the loss of Shp2 inhibited oligodendrocyte differentiation. This study did not report any data from the brains of these transgenic animals. Another study examined Shp2 function in oligodendrocytes in the brain using the Olig2-Cre transgenic mouse, demonstrating that OPC generation was reduced in the absence of Shp2, but this study did not examine differentiation effects in the absence of Shp2 (Ehrman et al., 2014). The data presented in the current study suggest that oligodendrocyte Shp2 in the developing brain also promotes differentiation, which is consistent with its role in the developing spinal cord.

Previous reports were limited in examining oligodendrocyte Shp2 function during myelination due to early postnatal lethality. Both sets of animals only lived to 3 weeks of age, and data regarding myelination in the two conditional knock-out strains was only presented at P15 in both reports (Zhu et al., 2010; Ehrman et al., 2014). Using the CNP-Cre transgenic line, we were able to extend the lifespan of these animals by at least 1 week, allowing for a more detailed characterization of the role of Shp2 during late postnatal myelination. Our early myelination data were consistent with previous reports, demonstrating reduced myelination during the first 2 weeks of age. Importantly, by extending the lifespan of these animals, the current studies demonstrate that the inhibitory effect of Shp2 loss was compensated over time, in terms of the number of oligodendrocytes and of maturing oligodendrocytes. Interestingly, despite this, there was a unique phenotype at $\mathrm{P} 28$ where $\mathrm{CKO}$ animals had fewer myelinated axons with thicker myelin sheaths. This is in line with our initial hypothesis that Shp2 acts as a negative regulator of myelination.

The signaling mechanisms responsible for the increased myelin thickness observed were unexpected. The increased myelin per axon was not due to increased Akt/mTOR or ERK signaling, two signaling cascades that have previously been shown to regulate myelin thickness (Flores et al., 2008; Ishii et al., 2013). Similarly, Ehrman et al. (2014) demonstrated that a Shp2 gain-of-function mutation in oligodendrocytes increased ERK signaling, but, rather than increasing myelin production, this mutation actually resulted in fewer numbers of myelinated axons with myelin decompaction abnormalities. Thus, elevated ERK signaling in some contexts in not sufficient to cause myelin overproduction and in fact can be a negative signal.

In the current studies, rather than changes in Akt or Erk signaling, we observed significantly higher levels of FAK signaling coincident with the reduced numbers of myelinated axons, but with increased myelin thickness. FAK is a known substrate of Shp2 (Huang et al., 2012; Hartman et al., 2013) and has been shown to influence process extension during oligodendrocyte differentiation (Hoshina et al., 2007). It is expressed in oligodendrocyte lineage cells with localization to myelin membranes (Kilpatrick et al., 2000; Bacon et al., 2007; this article). We show that conditional knockout of Shp2 from developing oligodendrocytes resulted in increased levels of phospho-FAK Y397 expression in myelin processes. Furthermore, the conditional knockout of FAK from oligodendrocytes results in decreased CNS myelination (Forrest et al., 2009), which is consistent with our zebrafish inhibitor studies. Furthermore, FAK inhibition was able to rescue the increased myelin internode length observed when Shp2 is inhibited. We suggest a model in which Shp2 deletion/inhibition in oligodendrocytes during early myelination causes increased FAK phosphorylation and excess myelin thickness. The downstream effectors of FAK signaling, and how those effectors influence myelination, remain unknown.

While Shp2 loss during early myelination resulted in reduced numbers of myelinated axons with increased myelin thickness, the induced knockout of Shp2 during or after active myelination was insufficient to cause long-term changes in myelin maintenance, suggesting that Shp2 is dispensable for myelin maintenance. It is possible that induced Shp2 knockout caused an initial increase in myelin production that was later appropriately modulated during the 6 weeks after injections. However, this is unlikely due to the long half-life and slow turnover of myelin (Quarles et al., 2006). Another possibility is that Shp2 provides transient regulation of myelination, while another currently unknown protein provides sustained downregulation of myelination. The PNS uses this strategy of multiple negative regulators, with Dlg1 serving as a transient regulator of Schwann cell myelination and DDIT4 as a sustained regulator (Cotter et al., 2010; Noseda et al., 2013).

Finally, these studies are the first to show that oligodendrocyte Shp2 plays a functional role in CNS remyelination. Both the recruitment and differentiation of oligodendrocytes in the demyelinated spinal cord were delayed by Shp2 deletion, resulting in delayed remyelination, although eventual full recovery. The downstream signaling events that caused this delay remain to be determined. Similar delays in remyelination were observed in ERK2 conditional knock-out animals and were attributed to decreased translation of MBP (Michel et al., 2015). Thus, it is conceivable that while Shp2 knockout does not have a great effect on ERK signaling during development, but it could influence ERK signaling to control MBP translation during myelin regeneration. 
In conclusion, Shp2 is an important mediator of oligodendrocyte differentiation and myelination, both during developmental myelination as well as in myelin regeneration. We provide important insight into the signaling mechanisms regulating myelination and propose that Shp2 acts as a transient brake to the myelination process. Furthermore, the role of Shp2 in regulating oligodendrocyte differentiation following demyelination has important therapeutic implications, as differentiation failure is a pathological feature in multiple sclerosis and thought to contribute to remyelination failure as the disease progresses (Chang et al., 2002).

\section{References}

Ahrendsen JT, Macklin W (2013) Signaling mechanisms regulating myelination in the central nervous system. Neurosci Bull 29:199-215. CrossRef Medline

Bacon C, Lakics V, Machesky L, Rumsby M (2007) N-WASP regulates extension of filopodia and processes by oligodendrocyte progenitors, oligodendrocytes, and Schwann cells-implications for axon ensheathment at myelination. Glia 55:844-858. CrossRef Medline

Bechler ME, Byrne L, Ffrench-Constant C (2015) CNS myelin sheath lengths are an intrinsic property of oligodendrocytes. Curr Biol 25:2411-2416. CrossRef Medline

Buckley CE, Marguerie A, Alderton WK, Franklin RJ (2010) Temporal dynamics of myelination in the zebrafish spinal cord. Glia 58:802-812. CrossRef Medline

Chang A, Tourtellotte WW, Rudick R, Trapp BD (2002) Premyelinating oligodendrocytes in chronic lesions of multiple sclerosis. N Engl J Med 346:165-173. CrossRef Medline

Coskun V, Zhao J, Sun YE (2007) Neurons or glia? Can SHP2 know it all? Sci STKE 2007:pe58. CrossRef Medline

Cotter L, Ozçelik M, Jacob C, Pereira JA, Locher V, Baumann R, Relvas JB, Suter U, Tricaud N (2010) Dlg1-PTEN interaction regulates myelin thickness to prevent damaging peripheral nerve overmyelination. Science 328: 1415-1418. CrossRef Medline

Doerflinger NH, Macklin WB, Popko B (2003) Inducible site-specific recombination in myelinating cells. Genesis 35:63-72. CrossRef Medline

Ehrman LA, Nardini D, Ehrman S, Rizvi TA, Gulick J, Krenz M, Dasgupta B, Robbins J, Ratner N, Nakafuku M, Waclaw RR (2014) The protein tyrosine phosphatase Shp2 is required for the generation of oligodendrocyte progenitor cells and myelination in the mouse telencephalon. J Neurosci 34:37673778. CrossRef Medline

Fancy SP, Chan JR, Baranzini SE, Franklin RJ, Rowitch DH (2011) Myelin regeneration: a recapitulation of development? Annu Rev Neurosci 34: 21-43. CrossRef Medline

Flores AI, Narayanan SP, Morse EN, Shick HE, Yin X, Kidd G, Avila RL, Kirschner DA, Macklin WB (2008) Constitutively active Akt induces enhanced myelination in the CNS. J Neurosci 28:7174-7183. CrossRef Medline

Forrest AD, Beggs HE, Reichardt LF, Dupree JL, Colello RJ, Fuss B (2009) Focal adhesion kinase (FAK): a regulator of CNS myelination. J Neurosci Res 87:3456-3464. CrossRef Medline

Franklin KBJ, Paxinos G (2008) The mouse brain in stereotaxic coordinates, ed. 3. New York, NY: Academic Publishers.

Franklin RJ, Ffrench-Constant C (2008) Remyelination in the CNS: from biology to therapy. Nat Rev Neurosci 9:839-855. CrossRef Medline

Furusho M, Ono K, Takebayashi H, Masahira N, Kagawa T, Ikeda K, Ikenaka $\mathrm{K}$ (2006) Involvement of the Olig2 transcription factor in cholinergic neuron development of the basal forebrain. Dev Biol 293:348-357. CrossRef Medline

Genoud S, Lappe-Siefke C, Goebbels S, Radtke F, Aguet M, Scherer SS, Suter U, Nave KA, Mantei N (2002) Notch1 control of oligodendrocyte differentiation in the spinal cord. J Cell Biol 158:709-718. CrossRef Medline

Grossmann KS, Wende H, Paul FE, Cheret C, Garratt AN, Zurborg S, Feinberg K, Besser D, Schulz H, Peles E, Selbach M, Birchmeier W, Birchmeier C (2009) The tyrosine phosphatase Shp2 (PTPN11) directs Neuregulin1/ErbB signaling throughout Schwann cell development. Proc Natl Acad Sci U S A 106:16704-16709. CrossRef Medline

Hartman ZR, Schaller MD, Agazie YM (2013) The tyrosine phosphatase SHP2 regulates focal adhesion kinase to promote EGF-induced lamellipodia persistence and cell migration. Mol Cancer Res 11:651-664. CrossRef Medline

Hildebrand C, Remahl S, Persson H, Bjartmar C (1993) Myelinated nerve fibres in the CNS. Prog Neurobiol 40:319-384. CrossRef Medline

Hoshina N, Tezuka T, Yokoyama K, Kozuka-Hata H, Oyama M, Yamamoto T (2007) Focal adhesion kinase regulates laminininduced oligodendroglial process outgrowth. Genes Cells 12:12451254. CrossRef Medline

Huang YS, Cheng CY, Chueh SH, Hueng DY, Huang YF, Chu CM, Wu ST, Tai MC, Liang CM, Liao MH, Chen CC, Shen LH, Ma KH (2012) Involvement of SHP2 in focal adhesion, migration and differentiation of neural stem cells. Brain Dev 34:674-684. CrossRef Medline

Ishii A, Fyffe-Maricich SL, Furusho M, Miller RH, Bansal R (2012) ERK1/ ERK2 MAPK signaling is required to increase myelin thickness independent of oligodendrocyte differentiation and initiation of myelination. J Neurosci 32:8855-8864. CrossRef Medline

Ishii A, Furusho M, Bansal R (2013) Sustained activation of ERK1/2 MAPK in oligodendrocytes and Schwann cells enhances myelin growth and stimulates oligodendrocyte progenitor expansion. J Neurosci 33:175-186. CrossRef Medline

Jeffery ND, Blakemore WF (1995) Remyelination of mouse spinal cord axons demyelinated by local injection of lysolecithin. J Neurocytol 24:775781. CrossRef Medline

Kilpatrick TJ, Ortuño D, Bucci T, Lai C, Lemke G (2000) Rat oligodendroglia express c-met and focal adhesion kinase, protein tyrosine kinases implicated in regulating epithelial cell motility. Neurosci Lett 279:5-8. CrossRef Medline

Kimmel CB, Ballard WW, Kimmel SR, Ullmann B, Schilling TF (1995) Stages of embryonic development of the zebrafish. Dev Dyn 203:253-310. CrossRef Medline

Kuo E, Park DK, Tzvetanova ID, Leiton CV, Cho BS, Colognato H (2010) Tyrosine phosphatases Shp1 and Shp2 have unique and opposing roles in oligodendrocyte development. J Neurochem 113:200-212. CrossRef Medline

Lafrenaye AD, Fuss B (2010) Focal adhesion kinase can play unique and opposing roles in regulating the morphology of differentiating oligodendrocytes. J Neurochem 115:269-282. CrossRef Medline

Lappe-Siefke C, Goebbels S, Gravel M, Nicksch E, Lee J, Braun PE, Griffiths IR, Nave KA (2003) Disruption of Cnp1 uncouples oligodendroglial functions in axonal support and myelination. Nat Genet 33:366-374. CrossRef Medline

Liu X, Li Y, Zhang Y, Lu Y, Guo W, Liu P, Zhou J, Xiang Z, He C (2011) SHP-2 promotes the maturation of oligodendrocyte precursor cells through Akt and ERK1/2 signaling in vitro. PLoS One 6:e21058. CrossRef Medline

Marin TM, Keith K, Davies B, Conner DA, Guha P, Kalaitzidis D, Wu X, Lauriol J, Wang B, Bauer M, Bronson R, Franchini KG, Neel BG, Kontaridis MI (2011) Rapamycin reverses hypertrophic cardiomyopathy in a mouse model of LEOPARD syndrome-associated PTPN11 mutation. J Clin Invest 121:1026-1043. CrossRef Medline

Michel K, Zhao T, Karl M, Lewis K, Fyffe-Maricich SL (2015) Translational control of myelin basic protein expression by ERK2 MAP kinase regulates timely remyelination in the adult brain. J Neurosci 35:7850-7865. CrossRef Medline

Molineaux SM, Engh H, de Ferra F, Hudson L, Lazzarini RA (1986) Recombination within the myelin basic protein gene created the dysmyelinating shiverer mouse mutation. Proc Natl Acad Sci U S A 83:7542-7546. CrossRef Medline

Nagata N, Matsuo K, Bettaieb A, Bakke J, Matsuo I, Graham J, Xi Y, Liu S, Tomilov A, Tomilova N, Gray S, Young Jung DY, Ramsey JJ, Kim JK, Cortopassi G, Havel PJ, Haj FG (2012) Hepatic Src homology phosphatase 2 regulates energy balance in mice. Endocrinology 153:3158-3169. CrossRef Medline

Narayanan SP, Flores AI, Wang F, Macklin WB (2009) Akt signals through the mammalian target of rapamycin pathway to regulate CNS myelination. J Neurosci 29:6860-6870. CrossRef Medline

Navis AC, van den Eijnden M, Schepens JT, Hooft van Huijsduijnen R, Wesseling P, Hendriks WJ (2010) Protein tyrosine phosphatases in glioma biology. Acta Neuropathol 119:157-175. CrossRef Medline

Noseda R, Belin S, Piguet F, Vaccari I, Scarlino S, Brambilla P, Martinelli 
Boneschi F, Feltri ML, Wrabetz L, Quattrini A, Feinstein E, Huganir RL, Bolino A (2013) DDIT4/REDD1/RTP801 is a novel negative regulator of Schwann cell myelination. J Neurosci 33:15295-15305. CrossRef Medline Quarles RH, Macklin WB, Morell P (2006) Myelin formation, structure, and biochemistry. In: Basic neurochemistry: molecular, cellular and medical aspects (Siegel GJ, Albers RW, Brady ST, Price DL, eds), pp 51-72. New York, NY: Elsevier Academic.

Schindelin J, Arganda-Carreras I, Frise E, Kaynig V, Longair M, Pietzsch T, Preibisch S, Rueden C, Saalfeld S, Schmid B, Tinevez JY, White DJ, Hartenstein V, Eliceiri K, Tomancak P, Cardona A (2012) Fiji: an opensource platform for biological-image analysis. Nat Methods 9:676-682. CrossRef Medline

Trapp BD, Nishiyama A, Cheng D, Macklin W (1997) Differentiation and death of premyelinating oligodendrocytes in developing rodent brain. J Cell Biol 137:459-468. CrossRef Medline

Yamamura T, Konola JT, Wekerle H, Lees MB (1991) Monoclonal antibodies against myelin proteolipid protein: identification and characterization of two major determinants. J Neurochem 57:1671-1680. CrossRef Medline

Zhang SQ, Yang W, Kontaridis MI, Bivona TG, Wen G, Araki T, Luo J, Thompson JA, Schraven BL, Philips MR, Neel BG (2004) Shp2 regulates SRC family kinase activity and Ras/Erk activation by controlling Csk recruitment. Mol Cell 13:341-355. CrossRef Medline

Zhu Y, Park J, Hu X, Zheng K, Li H, Cao Q, Feng GS, Qiu M (2010) Control of oligodendrocyte generation and proliferation by Shp2 protein tyrosine phosphatase. Glia 58:1407-1414. CrossRef Medline 